NASA Technical Memorandum 89917

AIAA-87-1893

\title{
Wind Tunnel Performance Results of an Aeroelastically Scaled 2/9 Model of the PTA Flight Test Prop-Fan
}

George L. Stefko

Lewis Research Center

Cleveland, Ohio

Gayle E. Rose

Sverdrup Technology, Inc.

Lewis Research Center

Cleveland, Ohio

Gary G. Podboy

Lewis Research Center

Cleveland, Ohio

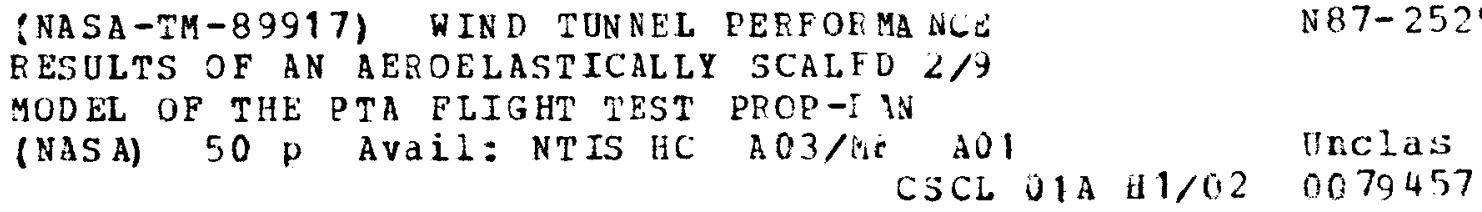

Prepared for the

23rd Joint Propulsion Conference

cosponsored by the AIAA, SAE, ASME, and ASEE

San Diego, California, June 29-July 2, 1987 
WINO TUNNEL PERFORMANCE RESULTS OF AN AEROELASTICALLY SCALED $2 / 9$ MODEL OF

\title{
THE PTA FLIGHT TEST PROP-FAN
}

\author{
George L. Stefko \\ National Aeronautics and Space Administration \\ Lewis Research Center \\ Cleveland, Ohio 44135 \\ Gayle E. Rose \\ Sverdrup Technology, Inc. \\ Lewis Research Center \\ Cleveland, Ohio 44135 \\ Gary G. Podboy \\ National Aeronautics and Space Administration \\ Lewis Research Center \\ Cleveland, Ohio 44135
}

\section{SUMMARY}

High speed wind tunnel aerodynamic performance tests of the SR-7A advanced Prop-Fan have been completed at the NASA Lewis Research Center in support of the Prop-Fan Test Assessment (PTA) flight test program. The $62.23 \mathrm{~cm}(24.5 \mathrm{in}$.) diameter adjustable-pitch aeroelastic model was tested at Mach numbers typical of climb and cruise (i.e., from 0.45 to 0.90 ) in the NASA Lewis 8 - by 6-Foot Wind Tunnel.

The SR-7A model was aeroelastically scaled to have the same structural characteristics as the $2.743 \mathrm{~m}(9 \mathrm{ft})$ diameter PTA flight test Prop-Fan. This Prop-Fan has eight blades and a cruise design operating condition of 0.80 Mach number, $10.66 \mathrm{~km}(35000 \mathrm{ft})$ I.S.A. altitude, $243.8 \mathrm{~m} / \mathrm{s}(800 \mathrm{ft} / \mathrm{sec})$ tip speed and a high power loading of $256.85 \mathrm{~kW} / \mathrm{m}^{2}\left(32.0 \mathrm{shp} / \mathrm{ft}^{2}\right)$.

At the cruise design condition, the SR-7A Prop-Fan had a high measured net efficiency of 79.3 percent. Further, it showed good aerodynamic performance over a wide range of Mach numbers $(0.45$ to 0.85$)$. Spanwise loading distributions obtained from wake survey measurements indicate that no significant aerodynamic problems exist when operating over a range of power loadings at Mach 0.80. Fluorescent oil flow photographs document a small leading edge vortex pattern near design conditions on the suction side of the $47^{\circ}$ swept SR-7A and $45^{\circ}$ swept SR-3 Prop-Fans but none on the unswept SR-2 Prop-Fan. In summary, this test shows that the SR-7A model performed aerodynamically very we 11 . Thus, we can expect the scaled $2.743 \mathrm{~m}(9 \mathrm{ft})$ diameter Prop-fan to also perform very well aerodynamically in the flight test program.

\section{INTRODUCTION}

The attractiveness of advanced turboprop propulsion results from its potential for very high efficiency at cruise speeds up to Mach 0.85 . A number of studies have been conducted by both NASA and industry to evaluate the potential of advanced high-speed turboprop propulsion for both civil and military appli-

cations. Numerous references to specific studies and summary results are listed in reference 1. Installed efficiencies for comparable-technology 
advanced turboprops and turbofans were used in most of these studies. Figure 1 compares the installed cruise efficiency of turboprop-powered and turbofanpowered propulsive systems over a range of cruise speeds. The efficiencies shown include the installation losses for both systems, namely, nacelle drag for the turboprop systems and fan-cowling external drag and fan airflow internal losses associated with inlet recovery and nozzle efficiency for the turbo fan systems. Conventional lower speed turboprops, such as the Electra, have installed efficiencies above 80 percent at speeds up to about Mach 0.5 , but can suffer from rapid decreases in efficiency above this speed because of increasing propeller-compressibility losses. These losses for propellers operating at high helical-tip Mach numbers are primarily the result of relatively thick blades ( 5 to 7 percent of chord at 75 -percent radius).

The advanced high-speed turboprop has the potential to delay these compressibility losses to a much higher cruise speed and achieve a relatively high performance to at least Mach 0.8 cruise. Although high-bypass-ratio turbofans exhibit their highest efficiency at cruise speeds near Mach 0.8 , their performance would still be significantly below that of the advanced turboprops. For example at Mach 0.8, the installed efficiency of the turbofan system would be about 65 percent, while the installed efficiency of the advanced turboprop would be about 75 percent. At lower cruise speeds, the efficiency advantage of the advanced turboprop would be even larger.

Figure 2, which shows block fuel savings as a function of trip-stage length, is a summary of the reference 1 studies. As shown in figure 2, block fuel savings depend on aircraft cruise speed and range. At Mach 0.8 cruise (which is represented by the bottom of the band), fuel savings range from about 15 to 25 percent for advanced turboprop aircraft when compared to equivalent technology turbofan aircraft. The larger fuel savings occur at the shorter operating ranges, where the mission is climb and descent dominated. Because of the lower operating speeds encountered during climb and descent, turboprops have an even larger performance advantage over turbofans when operating at these conditions than when operating at Mach 0.8 cruise. In a similar manner, a larger fuel savings is possible at Mach 0.7 cruise (which is represented by the top of the band in fig. 2). At this lower cruise speed, fuel savings range from about 20 to 30 percent. Even larger fuel savings may be possible by recovering the propeller swirl loss from these single-rotation turboprops. Swirl-recovery vanes and counter-rotation are two promising concepts for recovering swirl loss. In addition, advanced airfoils can also improve performance. All these concepts are currently under study, with wind tunnel tests and/or flight tests underway at NASA Lewis and in the industry.

In view of the attractive fuel-savings potential of the advanced high-speed turboprop propulsion system, the National Aeronautics and Space Administration has established the Advanced Turboprop Program. The purpose of this major research and technology program (ref. 2) is to establish the technology base required to lead to the application of the advanced turboprop propulsion system concept. One phase of this overall program is the Large-Scale Advanced PropFan Program (LAP) (ref. 3) which includes the design, fabrication and ground testing of a $2.743 \mathrm{~m}(9 \mathrm{ft})$ diameter propeller. After having completed the ground testing, this Prop-Fan has started flight testing on a test bed Gulfstream Il airplane as shown in figure 3. To support this filight test program, an aeroelastically-scaled, $62.23 \mathrm{~cm}$ (24.5 in.) model of this Prop-fan, called the SR-7A, was built to allow for an early determination of the aeroelastic characteristics of the flight test Prop-Fan and also to measure the aerodynamic 
performance of this Prop-Fan which would not be done in the fight test program. This SR-7A Prop-Fan was tested in the NASA Lewis 8-by 6-Foot Wind Tunnel on the Lewis propeller test rig. This report presents the wind tunnel aerodynamic test results for the SR-7A Prop-Fan in the climb and cruise flight regimes (i.e., Mach 0.45 to 0.90 ).

\section{AERODYNAMIC DESIGN CONCEPTS AND MODEL DESCRIPTION}

To achieve the previously described fuel savings, the propeller on the advanced turboprop would have to incorporate a number of unique design features that would enhance propeller performance and lower source noise. These unique design features are required to reduce blade-compressibility losses and attain high efficiency in the transonic Mach number regime. A propeller designed for a cruise Mach number of 0.80 at an altitude above $9.144 \mathrm{~km}(30000 \mathrm{ft}$ ) would have local blade Mach numbers from just over 0.8 at the blade hub to supersonic (near 1.15) at the blade tip. The inherent detrimental effects of these high Mach numbers on performance are minimized by some of the design concepts shown in figure 4 .

These concepts include proper shaping of the nacelle to reduce inboardblade Mach number, blade sweep to reduce outboard-blade local Mach number, thinner blades to increase drag-rise Mach number, and spinner area ruling to prevent inboard blade choking. To hold propeller diameter to a reasonable value, a high power (or disk) loading, and concomitantly, a large number of blades ( 8 to 10$)$ and increased chord length are required. The inboard portion of the propeller then operates as a cascade rather than as isolated airfoils. These design concepts are incorporated in the model and flight test propeller that are described in more detail in this report.

The flight test propeller was designed for an operating condition of Mach 0.80 , a $10.668 \mathrm{~km}(35000 \mathrm{ft})$ I.S.A. altitude, a $243.8 \mathrm{~m} / \mathrm{s}(800 \mathrm{ft} / \mathrm{sec})$ tip speed, and a power loading of $256.85 \mathrm{~kW} / \mathrm{m}^{2}\left(32.0 \mathrm{shp} / \mathrm{ft}^{2}\right)$. The model propeller was designed to operate in the wind tunnel with the same aeroelastic characteristics and blade geometry as the flight test propeller operating at cruise. The model has a diameter of $62.23 \mathrm{~cm}(24.5 \mathrm{in}$.$) while the flight test$ propeller has a $2.743 \mathrm{~m}(9 \mathrm{ft})$ diameter. The overall design characteristics and planform of the model are presented in table $I$.

The aerodynamic blade-shape characteristics are presented for the $41^{\circ}$ swept SR-7A propeller in figure 5. The blade characteristics shown represent the best estimate of the deflected operating shape the blade will have at the cruise design position. The design lift coefficient $C_{L D}$, thickness ratio $t / b$, chord ratio $b / D$, twist angle $\Delta \beta$, and cone angle $\phi$ were established to provide a loading distribution at the design condition which would allow for structural aeroelastic stability, high efficiency and low noise.

The airfoil sections selected for the SR-7A blade design are NACA Series 16, from the tip to the 57-percent radius, and NACA Series 65 with circular arc (CA) mean camber lines, from the 41-percent radius to the root (with a transition fairing between them). These airfoils were chosen for their high critical Mach numbers and their wide, low drag buckets. 
The spinner and nacelle shape are designed to alleviate blade-root choking and minimize compressibility drag rise. The spinner incorporates area ruling and blends into the nacelle. The nacelle has a maximum diameter equal to 35 percent of the model propeller diameter. The dimensions of the SR-7A Spinner, nacelle and windscreen are listed in table II. More SR-7A design information is presented in reference 4 .

The performance data were acquired for a model configuration which had the gaps between the propeller blade roots and the hub surface sealed. The gaps were disproportionately large for the model and were sealed to be more representative of a full-scale propeller.

\section{SR-7A PROPELLER TEST PROGRAM}

\section{Wind Tunnel}

The SR-7A propeller model tests were conducted in the NASA Lewis 8-by 6-Foot wind Tunnel. The $8 \mathrm{ft}$ modified test section of the facility was designed for transonic testing and incorporated a perforated test section with 6.2 percent porosity to minimize model-wall interactions. The normal operating range of this test section is from Mach 0.36 to 2.0. For this test, the tunnel was run in the propulsion mode where outside air is drawn in upstream and is exhausted downstream of the model. Additional details of this facility may be found in reference 5 .

\section{Propeller Test Rig (PTR)}

All propeller testing was done with the Propeller Test Rig (PTR) which was designed and developed specifically for conducting research on advanced propel. lers in the Lewis 8 -by 6-foot and 10-by 10-Foot wind Tunnels. The PTR was strut-mounted from the ceiling in the tunnel test section. The PTR and the SR-7A model mounted in the tunnel are shown in figure 6 while a cutaway view of the PTR is presented in figure 7. The model was driven by a three stage air turbine utilizing high pressure air at $3.1 \times 10^{6} \mathrm{~N} / \mathrm{M}^{2}$ (450 psi) and heated to $367 \mathrm{~K}\left(660^{\circ} \mathrm{R}\right)$. The turbine is capable of delivering nearly $746 \mathrm{~kW}$ ( $\left.1000 \mathrm{hp}\right)$ to the propeller model.

The PTR force measuring system is a rotating balance which measures thrust and torque of the propeller and spinner. When corrected for internal pressure tares, nacelle interaction forces and spinner forces, the PTR measurement results in the net forces produced by the propeller blades.

Extensive static calibrations of the water cooled rotating balance were done in previous tests and were repeated prior to the SR-7A propeller test. Along with the repeated calibrations, new calibrations were done which incorporated several different temperature settings of the balance cooling water to determine the effect of temperature on the balance. Limited test entry time prevented repeating the dynamic calibrations during the entry. Therefore the dynamic calibrations were based on previous test data. These calibrations consisted of using weights to apply thrust loads through a water cooled bearing to determine the effect of rotational speed on the thrust. 
The net propeller thrust is defined as the propulsive force of the blades operating in the presence of the spinner and nacelle flow field without the increase in thrust due to the mutual interaction between the propeller blades, the spinner and the nacelle. In order to correct for these interactive forces, model tare tests are done without the propeller blades to evaluate both the external spinner aerodynamic drag and the nacelle pressure drag.

In tare tests, the spinner and propeller blades are replaced by a "dummy" hub which has no holes for the blades. A special series of experimental runs are made to define the spinner aerodynamic and nacelle pressure drag for the same range of tunnel Mach numbers as would be tested with the model blades. As shown in figure $8(a)$, the spinner drag $\left(D_{S T}\right)$ is measured directly from the force balance and corrected for the internal pressure area forces. The nacelle pressure drag ( $D_{N T}$ ), is determined by pressure integration of the longitudinal rows of area-weighted pressure orifices.

Due to the time limitations of this test, it was decided not to do these reference runs but to use similar data from a large number of previous tests. Therefore the nacelle pressure drag tare and the spinner drag tare were taken from previous tests. The nacelle pressure drag tare of the PTR has been we 11 documented in previous tests and the variability was very small. The potential error at the design point efficiency of 79.3 percent was estimated to be 0.1 percent. The previously tested SR-6 and SR-6Al spinner shapes were slightly smaller and larger, respectively, than the SR-7A spinner. The SR- 6 spinner drag data, increased by about 30 percent of the difference in drag between the SR-6 and SR-6AT curves, was used. The spinner drag coefficient is shown in figure 9. Any potential spinner drag error at the design point effi. ciency of 79.3 percent was estimated to be 0.2 percent.

With the propeller blades installed and thrusting, the force balance measures the algebraic sum of the propeller thrust, the spinner drag, and the internal pressure area forces. The model forces are as shown in figure $8(b)$. The uncorrected propeller thrust (TPROP in fig. $8(b)$ ) is defined as follows:

$$
T_{P R O P}=F B-\sum P A_{1 N T}+D_{S}
$$

When this uncorrected propeller thrust is corrected for the change in spinner drag $\left(\Delta D_{S}\right)$ between the powered data (fig. $\left.8(b)\right)$ and the tare data (fig. $8(\mathrm{a})$ ), $\Delta D S$ can be determined from:

$$
\Delta D_{S}=D_{S}-D_{S T}
$$

The apparent thrust of the propeller is obtained from:

or

$$
T_{A P P}=T_{P R O P}-\Delta D_{S}
$$

$$
T_{A P P}=F B-\sum P A_{I N T}+D_{S T}
$$

where

$$
P A_{I N T}=\left(p-p_{0}\right) A_{I N T}
$$


Next, the nacelle pressure drag is obtained from nacelle surface pressure integrations:

$$
D_{N}=\int\left(p_{N}-p_{0}\right) d A_{N}
$$

Then, the change in nacelle pressure drag, $\Delta D_{N}$, is obtained from the difference between these and the tare run pressure integrations:

$$
\Delta D_{N}=D_{N}-D_{N T}
$$

And finally, the net thrust is obtained by subtracting the change in nacelle pressure drag from the apparent thrust:

$$
T_{N E T}=T_{A P P}-\Delta D_{N}
$$

\section{TEST RESULTS}

The SR-7A Prop-Fan model was tested at zero angle of attack over a range of Mach numbers from 0.45 to 0.90 and at blade angles $\left(B_{0} .75 \mathrm{R}\right)$ of $57.7^{\circ}, 60.2^{\circ}$ and $63.3^{\circ}$. The blade angle, measured at 75 percent of the propeller radius, becomes $90^{\circ}$ when the chord of that airfoll section is aligned directiy with the flight direction. At each of the three blade angles tested, model thrust and power were measured over a range of Mach numbers and rotational speeds.

The Mach number/blade angle combinations tested are listed in table III. At each blade angle/Mach number combination, measurements were taken over an RPM range from windmill to a maximum of 9000 RPM. Blade stress, rig power and/or vibrations limits did occasionally prevent reaching the rig's maximum limit of 9000 RPM. Each rotational speed setting constituted a test point.

Two of the eight blades were instrumented with two strain gauges each to monitor blade stresses for safety. A correction to propeller efficiency for these strain gauges, based on previous propeller tests, was used to correct the data. This correction varied from 0.40 percent at Mach 0.45 to 0.51 percent at Mach 0.80 to 0.78 percent at Mach 0.90 .

The SR-7A aerodynamic propeller performance is presented in figures 10 to 16 for the freestream Mach numbers of $0.45,0.60,0.70,0.75,0.80,0.85$, and 0.90 . These figures present the propeller net efficiency (nnet) and power coefficient $\left(C_{p}\right)$ versus advance ratio $(J)$ for a given blade angle. Power coefficient and advance ratio are defined as:

$$
\begin{gathered}
c_{p}=\frac{p}{\rho_{0} n^{3} D^{5}} \\
J=\frac{v_{0}}{n D}
\end{gathered}
$$


In these figures the performance of the propeller is expressed in terms of net efficiency which corresponds to the net propulsive thrust produced with the propeller operating in the velocity field of the nacelle and spinner. Net efficiency is defined as:

$$
n_{N E T}=\frac{\text { Net Thrust } x \text { Freestream Velocity }}{\text { Shaft Power }}
$$

and in dimensionless form:

$$
\eta_{\text {NET }}=\frac{{ }_{C_{\text {NET }}} \mathrm{J}}{c_{p}}
$$

where,

$$
c_{T_{N E T}}=\frac{{ }_{N E T}}{\rho_{0} n^{2} D^{4}}
$$

Figures 10 to 16 show that the SR-7A Prop-Fan has high efficiency over a wide range of Mach numbers (0.45 to 0.90 ) and blade angles $\left(57.7^{\circ}\right.$ to $\left.63.3^{\circ}\right)$.

The data repeatability can be seen in figures 10 to 16 . There are withina-run repeat points on all these figures. In particular, the typical repeat data points show net efficiency changes of \pm 0.5 percent or less. For two separate runs, the data in figure 15 at Mach 0.85 and a blade angle of $63.3^{\circ}$ is seen to repeat within \pm 0.5 percent. Thus the data show the repeatability is good for this rotating thrust and torque measuring system.

The SR-7A Prop-Fan performance at the design Mach number of 0.80 is presented in figure 14. At the design advance ratio of 3.06 , power coefficient of 1.45 , and 100 percent design power loading parameter $\left(C_{p} / J^{3}=0.0506\right)$, the propeller design net efficiency is 79.3 percent. In figure 17 , the measured net efficiency is compared with the predictions from reference 6 . The predicted performance at the design power coefficient of 1.45 is 79.4 percent which agrees well with the measured efficiency of 79.3 percent.

A propeller efficiency data comparison from reference 7 is shown in figure 18 along with the efficiency results from the SR-7A test. The ideal and measured net efficiency are shown as a function of Mach number. The measured efficiency level of the SR-7A model is consistentiy higher than that of the SR-3. These two models have similar planform shapes and were designed with airfoils from the same family. At Mach 0.80 , the SR-7A has a higher measured efficiency of 79.3 percent compared to the SR-3 measured efficiency of 78.6 percent.

The ideal efficiencies of these two models are 87.0 percent for the SR-7A and 85.3 percent for the SR-3. Ideal efficiency represents the performance of an optimally loaded propeller with no blade drag. Differences between ideal and measured net efficiency can be attributed to losses due to drag, compressibility and non-optimum spanwise blade loading distribution. These losses associated with the SR-7A at Mach 0.80 cause a difference in ideal and measured 
net efficiency that is about one percent greater than that of the SR- 3 . This indicates that the aerodynamic losses of the SR-7A are higher than the SR- 3 .

In the SR-7A design, the structural and aeroelastic stability characteristics were favored over the aerodynamic performance design parameters. This design philosophy resulted in the tip not being swept on the helix as was done with the SR-3 propeller. Also the sweep was reduced and thickness increased resulting in further aerodynamic design compromises. In addition, these blades were made of composite materials instead of titanium. The greater uncertainties in composite structural analysis make it more difficult to predict the required blade shape for fabrication to yield the desired shape at the design operating conditions. Since the airfoils were from the same family as those used on the SR-3 propeller, the slightly higher aerodynamic losses were probably due to a combination of the above mentioned factors. Nevertheless, the SR-7A Prop-fan still has the highest measured efficiency of any single rotation propeller at their respective design points. This is primarily due to its lower design loading.

Since turboprops are actually operated at constant rotational tip speed, the aerodynamic performance data can further be examined by looking at the variation of net propeller efficiency with power loading and rotational tip speed. The nondimensional wind tunnel data were used to calculate dimensional tip speed and power loading conditions at $10.668 \mathrm{~km}(35000 \mathrm{ft}$ ) I.S.A. altitude. These performance data are presented in figures 19 to 23 at tip speeds from $213.4 \mathrm{~m} / \mathrm{sec}(700.0 \mathrm{ft} / \mathrm{sec})$ to $259.1 \mathrm{~m} / \mathrm{sec}(850.0 \mathrm{ft} / \mathrm{sec})$ and for Mach numbers from 0.60 to 0.85 . The flight test propeller was designed for an operating condition of Mach 0.80 with a power loading of $256.85 \mathrm{~kW} / \mathrm{m}^{2}\left(32.0 \mathrm{hp} / \mathrm{ft} \mathrm{t}^{2}\right)$ and a tip speed of $243.84 \mathrm{~m} / \mathrm{s}(800.0 \mathrm{ft} / \mathrm{sec})$ at $10.668 \mathrm{~km}(35000 \mathrm{ft}) 1 . S . A$. altitude. At this design condition, figure 22 shows that the SR-7A did achieve a high efficiency of 79.3 percent not only at a tip speed of $243.8 \mathrm{~m} / \mathrm{sec}$ $(800 \mathrm{ft} / \mathrm{sec})$ but also at $259.1 \mathrm{~m} / \mathrm{sec}(850 \mathrm{ft} / \mathrm{sec})$.

These data are also compared as a function of Mach number in figures 24 to 26. These figures show that the SR-7A Prop-Fan not only performs well at its design condition, but also retains a high level of propeller efficiency over a wide range of Mach numbers from 0.60 to 0.85 and power loadings from $240 \mathrm{~kW} / \mathrm{m}^{2}$ $\left(30 \mathrm{hp} / \mathrm{ft}^{2}\right)$ to $320 \mathrm{~kW} / \mathrm{m}^{2}\left(40 \mathrm{hp} / \mathrm{ft}^{2}\right)$.

\section{Survey Probe Test Results}

To obtain detailed information of the flowfield developed by the SR-7A Prop-Fan, a translating wake survey probe was used to measure the radial distributions of static and total pressure and total temperature in the wake of the prop for a series of different tunnel and model operating conditions. When combined with the tunnel freestream conditions, these measurements were used to compute the spanwise distributions of elemental thrust and power coefficients, $d C_{T} / d(r / R)$ and $d C_{p} / d(r / R)$. The radial distributions of axial, radial and tangential velocity and the wake flow angularity are also obtainable from these measurements. The probe measurements, therefore, provide a more detailed understanding of the Prop-Fan performance than can be had with the rotating balance, which provides only the integrated thrust and power coefficients, $C_{T}$ and $C p$. The spanwise distributions of the thrust and power coefficients as computed from the probe data can be used to determine if the Prop-fan blades 
are being loaded as designed and to suggest possible explanations for any discrepancies which may occur between the predicted and measured performance. In the present investigation, the spanwise distributions of total and static pressure, total temperature, thrust, power, and swirl angle will be presented for the SR-7A Prop-Fan operating at four different levels of the loading parameter $\mathrm{Cp} / \mathrm{J}^{3}$, while at the freestream Mach number of 0.80 .

The probe used to acquire the data behind the SR-7A Prop-Fan is a $f$ ive pressure/one temperature combination probe. A photograph of the probe and the probe support strut mounted from the wind tunnel floor is shown in figure 27. A close-up view of the probe is seen in figure 28 . During the SR-7A testing the probe cone tip was located at an axial position $15.3 \mathrm{~cm}(6.02 \mathrm{in}$.$) down-$ stream of the pitch change axis of the SR-7A blades and in a vertical plane that passed through the centerline of the model. The probe could be traversed radially from its retracted position (approximately $10 \mathrm{~cm}(4.0 \mathrm{in.}$ ) beyond the blade tip) up to the nacelle surface. A typical radial scan of data consisted of the acquisition of one sample of the thermocouple and four samples of each pressure port at each of nineteen radial positions with the tunnel and model operating conditions held constant. The four samples of each pressure port taken at each radial location were averaged together and subjected to the cali. bration curvefits of the probe to yield radial distributions of static and total pressure, yaw, radial flow angle and, after combination with the temperature measurements, the three components of velocity. Radial surveys were made both in the wake of the prop with the blades thrusting and, for reference, about the bare nacelle with the blades removed from the hub.

Radial distributions of the total pressure, static pressure and total tem. perature in the wake of the Prop- $F$ an as determined from the survey probe measurements are shown in figures 29 to 31 , respectively. Four different curves are presented on each of these figures corresponding to the cases of the Prop-fan operating near 75, 100, 125 and 150 percent of the design value of $\mathrm{Cp} / \mathrm{J}^{3}=0.0506$. The data presented were acquired at the freestream Mach number of 0.80 and with the $3 / 4$ radius blade angle set at $60.2^{\circ}$. The probe data presented herein corresponds to an axial location $15.3 \mathrm{~cm}(6.02 \mathrm{~m})$ downstream of the pitch change axis of the Prop-Fan blades. As can be seen from figures 29 and 37 , the total pressure and total temperature distributions are smooth and, as expected, tend to increase everywhere along the blade span as the power loading parameter $\mathrm{Cp} / \mathrm{J}^{3}$ is increased. The static pressure distributions of figure 30 indicate that the static pressure measured downstream of the propeller is lower than the freestream value at all radial locations, even outside the Prop-fan slipstream. This is primarily a result of the slight decrease in cross-sectional area at this axial location due to the presence of the mode 1 .

The swirl angle computed from the probe measurements is shown plotted against nondimensional radius $(r / R)$ in figure 32 for the same four test conditions. The change in the swirl measured by the probe between the blades-on and blades-off configurations is represented by these curves, the levels of which have been adjusted slightiy so the swirl at the outermost radius vanishes. The data was processed in this manner to minimize any bias errors in the swirl measurement due to probe misalignment. As can be seen from figure 32, a peak of approximately $4.5^{\circ}$ of swirl was measured for the test case near $c_{p} / J^{3}=100$ percent. Also, the amount of swirl imparted to the flowfield increases as the loading parameter $\mathrm{Cp} / \mathrm{J}^{3}$ is increased, with the maximum swirl of approximately $6^{\circ}$ 
occurring at the highest loading level. This trend is to be expected since swirl is related to the angular momentum change experienced by the flow and, hence, to the power output of the Prop-Fan.

The spanwise variations of the elemental thrust coefficient, $d C_{T} / d(r / R)$, for the four test conditions are shown plotted in figure 33, while the power loading distributions are plotted in figure 34 . A steady, quasi-one-dimensional momentum analysis was used to calculate the thrust distributions, while the power loadings were determined from the stagnation enthalpy increase across the PropFan. All of the curves plotted on these two figures are smooth and show the gradual increase in loading with radius characteristic of single rotating propellers. The radial location of the peaks of these curves appears to be relatively independent of loading level and occurs between the 85 and 90 percent span locations in all cases. These two figures clearly show the expected increase in the spanwise loading level as $\mathrm{Cp} / \mathrm{J}^{3}$ is increased.

The integrated thrust and power coefficients which result from summing the areas under the $d C_{T} / d(r / R)$ and $d C_{p} / d(r / R)$ distributions are given in table IV for each of the four test conditions. Also given in table IV are the effi. ciencies calculated from these coefficients and, for comparison, the coefficients and efficiencies determined from the force balance measurements. The balance measured apparent thrust coefficients and the corresponding apparent efficiencies are tabulated rather than the net values since the probe is more likely to be measuring the apparent thrust. Note that in each of the four test cases the apparent efficiencies, the apparent thrust coefficients, and the power coefficients computed from the probe and force balance measurements agree to within 4.3 percent. This is considered to be very good agreement since the accurate determination of these quantities from survey probe measurements places stringent requirements on the probe's ability to detect the small changes in the flowfield produced by the Prop-Fan. This good agreement between the two measurement systems suggests that both the shapes and the levels of the $d C_{T} / d(r / R)$ and $d C_{p} / d(r / R)$ versus nondimensional radius curves plotted in figures 33 and 34 are indicative of the true loading distributions.

\section{FLOW VISUALIZATION RESULTS}

A flourescent oil flow visualization study was conducted on the SR-2 and SR- 3 and SR-7A Prop-Fans to determine if leading edge vortices exist and the effect of blade sweep on these vortices. The sweep of the three tested propellers varied from zero sweep for the SR-2 Prop-Fan to 41 degrees of tip sweep for the SR-7A Prop-Fan to 45 degrees of tip sweep for the SR-3 Prop-Fan. Figures 35 to 36 show the suction side of the SR-2 blade run at Mach $0.60(\mathrm{~J}=3.01$, $\left.C_{p}=1.59, B_{0.75 R}=59.3^{\circ}\right)$ and $0.80\left(\mathrm{~J}=3.03, C_{p}=1.69, B_{0.75 R}=59.3^{\circ}\right) \mathrm{high}$ power conditions. No leading edge vortex is evident on either figure nor on the other side (not shown) of the blade. Figure 37 presents the SR-3 blade pressure side at Mach 0.80 windmill conditions $\left(J=4.52, C_{p}=0, \beta .75 R=62.0^{\circ}\right)$ to illustrate a full leading edge vortex pattern. At Mach $0.60(\mathrm{~J}=3.17$, $\left.C_{p}=2.14, B_{0.75 R}=62.0^{\circ}\right)$ and $0.80\left(J=3.21, C_{p}=1.99, B_{0.75 R}=62.0^{\circ}\right)$ high power conditions, a small leading edge vortex $c$ an be seen in figures 38 and 39 on the SR-3 blade suction sides but not on the pressure sides (not shown). These figures illustrate that the vortex is associated with the sweep of the blade. Similar photographs for the SR-7A suction side at Mach $0.60(J=3.18$, 
$\left.C_{p}=1.65, B_{0.75 R}=60.2^{\circ}\right)$ and $0.80\left(\mathrm{~J}=3.11, C_{p}=1.51, B_{0.75 R}=60.2^{\circ}\right)$

high power conditions are shown in figures 40 and 41 . A slight leading edge vortex also exists at the conditions tested for this blade.

The existence of this vortex is significant because it will alter the blade loading distribution. Presently, propeller prediction methods do not account for this vortex, but should take this phenomenon into account. A similar experiment was done on a swept counter-rotating propeller and a discussion of the leading edge vortex phenomena $c$ an be found in Ref. 8 . Thus, the leading edge vortex exists, is definitely caused by the sweep of the blade, and should be accounted for in prediction methods.

\section{SUMMARY OF RESULTS}

An aeroelastically-scaled $2 \mathrm{ft}$ model of the PTA flight test Prop-fan was tested in the NASA Lewis 8-by 6-Foot Wind Tunnel. The aerodynamic performance of this Prop-Fan was measured at zero angle of attack over a range of Mach numbers from 0.45 to 0.90 and for blade angles of $57.7^{\circ}, 60.2^{\circ}$, and $63.3^{\circ}$.

The data show that the SR-7A Prop-Fan has good aerodynamic performance over a wide range of Mach numbers $(0.45$ to 0.90$)$ and blade angles $\left(57.7^{\circ}\right.$ to $63.3^{\circ}$ ). It has a high measured net efficiency of 79.3 percent at its design Mach number of 0.80 , design power coefficient of 1.45 , advance ratio of 3.06 and 100 percent power loading $\mathrm{Cp} / \mathrm{J}^{3}=0.0506$.

The spanwise distributions of the elemental thrust and power coefficients computed from the wake survey probe measurements indicate that the SR-7A blades are properly loaded at 0.80 Mach over a range of power loadings from 75 to 150 percent of the design value of $C_{p} / J^{3}=0.0506$. The integrated thrust and power coefficients determined from the probe data agreed reasonably well with the measurements made by the rotating balance. A maximum of approximately $4.5^{\circ}$ of swirl was measured by the probe with the SR-7A Prop-Fan operating near its design condition. All of these wake survey results indicate that the SR-7A Prop-fan is performing well aerodynamically.

The fluorescent oil flow photographs show a small leading edge vortex pattern on the $47^{\circ}$ swept SR-7A and $45^{\circ}$ swept SR-3 Prop-Fans, but not on the unswept SR-2 Prop-Fan. These vortices alter the blade loading distributions and should be accounted for in propeller prediction codes.

In summary, this wind tunnel test shows the SR-7A Prop-Fan model performed aerodynamically very well. Thus, we can expect the larger scaled PTA Prop-Fan to also perform very well aerodynamically in the flight test program. 
A area, $\mathrm{m}^{2}$

Af blade activity factor,

$=6250 \int_{\left(r / R_{0}\right)}^{l .0}(b / D)(r / R)^{3} d(r / R)$

b elemental blade chord, m

CA circular arc mean line

$C_{L D}$ blade design lift coefficient

$C_{L i}$ integrated design lift coefficient,

$=4 \int_{\left(r / R_{0}\right) \text { at hub }}^{1.0} C_{L D}(r / R)^{3} d(r / R)$

$c_{p} \quad$ power coefficient $=P / \rho_{0} n^{3} D^{5}$

$c_{T}$ thrust coefficient $=T / \rho_{O} n^{2} D^{4}$

D propeller diameter at the design blade angle is $0.622 \mathrm{~m}(24.50 \mathrm{in.})$

$\mathrm{O}_{\mathrm{N}} \quad$ nacelle drag, $\mathrm{N}$

DS spinner drag, $\mathrm{N}$

dA elemental area, $\mathrm{m}^{2}$

FB force balance, $N$

$\mathrm{J}$ advance ratio $=\mathrm{V}_{0} / \mathrm{nD}$

M Mach number

$n$ rotational speed, rps

P power, $W$

PA pressure forces in the form $\left(p-p_{0}\right) \bullet$ Area, $N$

p pressure, $\mathrm{N} / \mathrm{m}^{2}$

PT total pressure, $\mathrm{N} / \mathrm{m}^{2}$ 


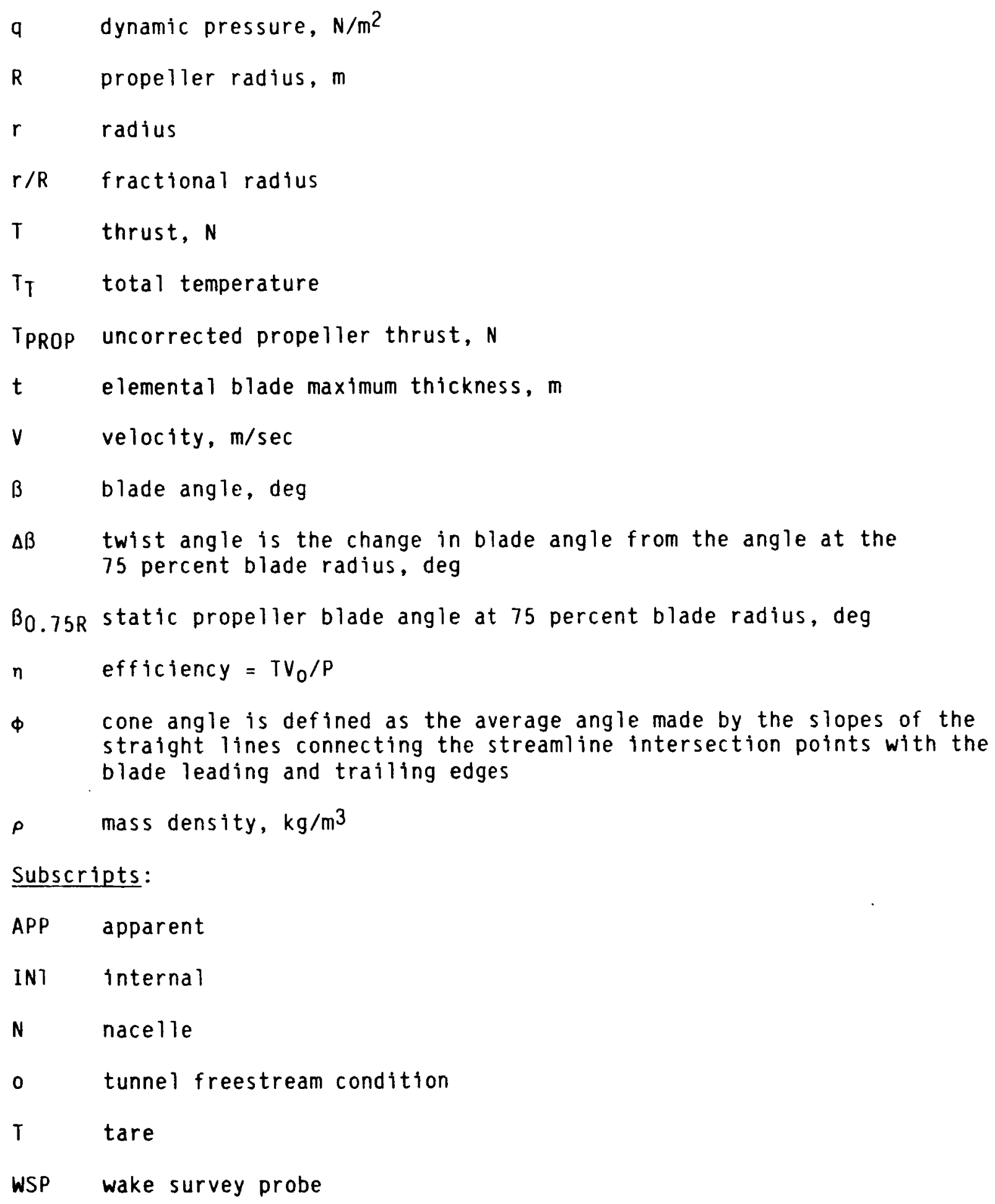


1. Jeracki, R.J.; Mikkeison, D.C.; and Blaha, B.J.: Wind Tunnel Performance of Four Energy Efficient Propeliers Designed for Mach 0.8 Cruise. SAE Paper 790573, Apr. 1979. (NASA TM-79124).

2. Whitlow, J.B. Jr.; and Sievers, G.K.: Fuel Savings Potential of the NASA Advanced Turboprop Program. NASA TM-83736, 1984.

3. Sagerser, D.A.; and Lundemann, S.G.: Large-Scale Advanced Propfan (LAP) Program Progress Report. AIAA Paper 85-1187, July 1985. (NASA TM-87067).

4. Nagle, D.; Auyeung, S.; and Turnberg, J.: SR-7A Aeroelastic Model Blade Design Report. (HSER-9251, United Technologies Corp.; NASA Contract NAS3-23051) NASA CR-174791, 1984.

5. Swallow, R.J.; and Aiello, R.A.: NASA Lewis 8- by 6-Foot Supersonic Wind Tunne1. NASA TM X-71542, 1974.

6. Parzych, D.; Shenkman, A.; and Cohen, S.: Large-Scale Advanced Propfan (LAP) Performance, Acoustic and Weight Estimation. (SP-06A83, Hamilton Standard; NASA Contract NAS3-23051) NASA CR-174782, 1984.

7. Mitchel1, G.A.: Experimental Aerodynamic Performance of an Advanced $40^{\circ}$ Swept 10 Bladed Propeller Model at Mach Numbers From 0.60 to 0.85 . NASA TM-88969, $198 \%$.

8. Vaczy, C.M.; and McCormick, D.G.: A Study of the Leading Edge Vortex on Counter-Rotating Prop-Fan Blades. ASME Paper 87-GT-234, June $198 \%$ 
TABLE I. - DESIGN CHARACTERISTICS OF THE SR-7A PROPELLER MODEL

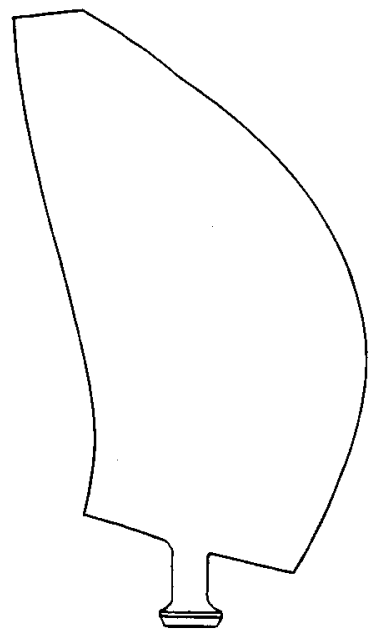

\begin{tabular}{|c|c|}
\hline Characteristic & SR-IA \\
\hline 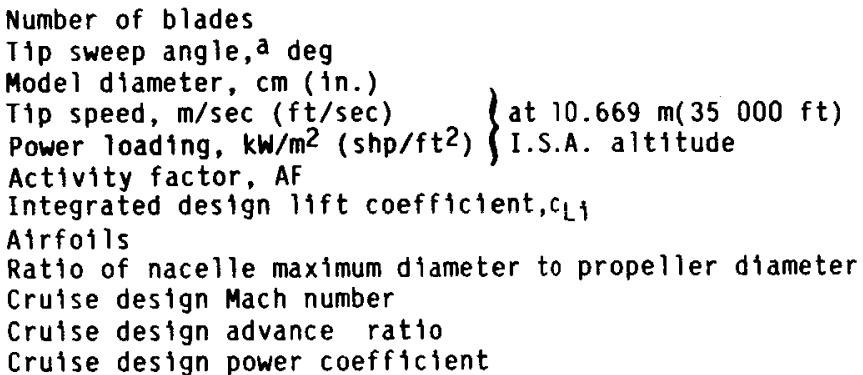 & $\begin{array}{r}8 \\
41 \\
62.23(24.5) \\
243.8(800) \\
256.85(32) \\
227 \\
0.202 \\
\text { NASA } 16 \text { and } 65 / \text { CA } \\
0.35 \\
0.80 \\
3.06 \\
1.45\end{array}$ \\
\hline
\end{tabular}

a Geometric measurement from planform. 
TABLE II. - DIMENSIONS OF SR-7A SPINNER, NACELLE, AND WINDSCREEN

$$
\left[R_{N}=11.05 \mathrm{~cm}(4.35 \mathrm{in.}) .\right]
$$
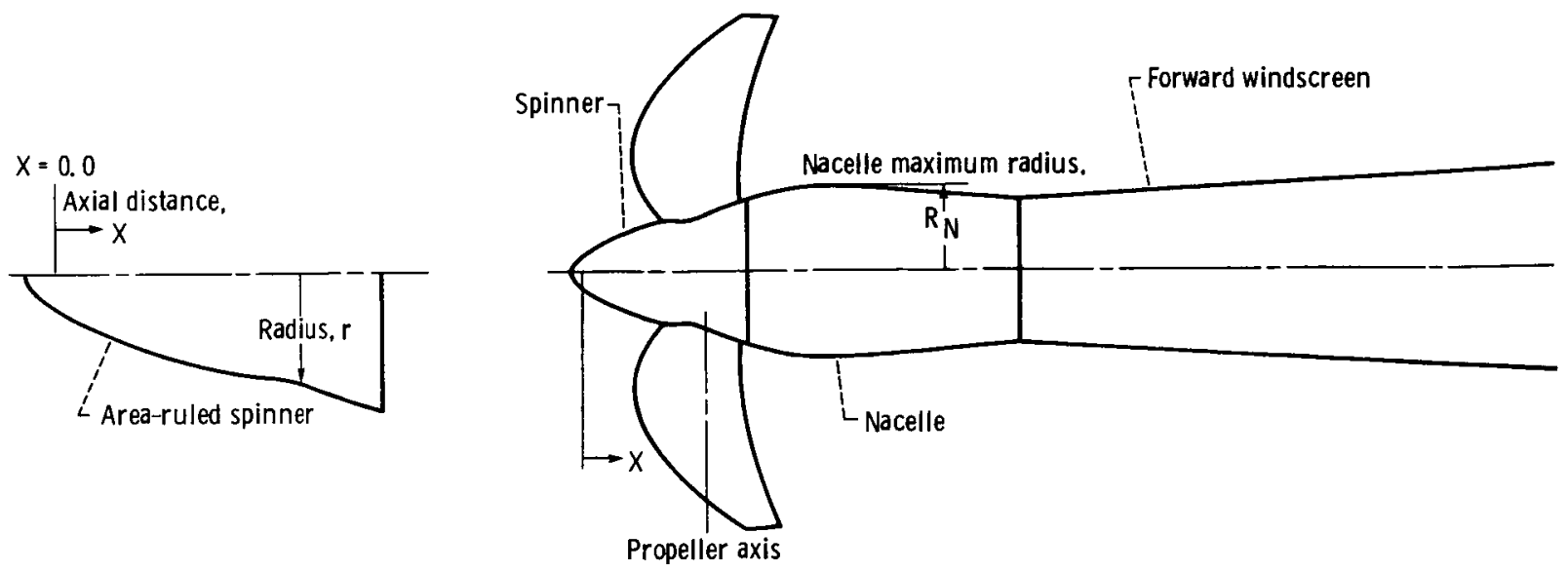

\begin{tabular}{|c|c|}
\hline \multicolumn{2}{|c|}{ Spinner } \\
SR-7A \\
\hline $41^{\circ}-$-swept blade \\
\hline$X / R_{N}$ & $r / R_{N}$ \\
\hline-0.232 & 0.000 \\
-.216 & .057 \\
-.764 & .148 \\
-.112 & .205 \\
-.060 & .250 \\
-.007 & .289 \\
.045 & .325 \\
.305 & .454 \\
.566 & .526 \\
.827 & .561 \\
$\cdot 1.088$ & .574 \\
1.244 & .579 \\
1.348 & .590 \\
1.505 & .622 \\
1.649 & .668 \\
1.924 & .764 \\
2.184 & .855 \\
\hline
\end{tabular}

\begin{tabular}{|c|c|c|c|}
\hline \multicolumn{4}{|c|}{ Nacelle } \\
\hline \multicolumn{2}{|c|}{ Forward } & \multicolumn{2}{|c|}{ Aft } \\
\hline$X / R_{N}$ & $r / R_{N}$ & $x / R_{N}$ & $r / R_{N}$ \\
\hline 2.199 & 0.860 & 3.366 & 0.999 \\
2.216 & .866 & 3.596 & .990 \\
2.239 & .873 & 3.825 & .975 \\
2.262 & .881 & 4.055 & .956 \\
2.285 & .888 & 4.285 & .933 \\
2.308 & .895 & 4.515 & .911 \\
2.331 & .902 & 4.745 & .894 \\
2.354 & .908 & 4.975 & .883 \\
2.377 & .915 & 5.205 & .874 \\
2.400 & .920 & 5.251 & .873 \\
2.423 & .926 & 5.297 & .871 \\
2.446 & .931 & 5.400 & .871 \\
2.561 & .946 &.--- & ---- \\
2.676 & .970 & ---- & ---- \\
2.791 & .982 & --- & --- \\
2.906 & .990 & ---- & ---- \\
3.136 & .999 & ---- & ---- \\
3.214 & 1.000 & --- & --- \\
\hline
\end{tabular}

\begin{tabular}{|l|l|}
\hline \multicolumn{2}{|c|}{$\begin{array}{c}\text { Forward } \\
\text { windscreen }\end{array}$} \\
\hline$x / R_{N}$ & $r / R_{N}$ \\
\hline 5.417 & 0.865 \\
8.659 & 1.046 \\
\hline
\end{tabular}


TABLE III. - SR-7A PROPELLER TEST MATRIX

\begin{tabular}{|c|c|c|c|}
\hline \multirow{2}{*}{$\begin{array}{c}\text { Mach } \\
\text { number }\end{array}$} & Blade angle at 75 percent radius deg \\
\cline { 2 - 4 } & 57.7 & 60.2 & 63.3 \\
\hline 0.45 & & $x$ & \\
.60 & $x$ & $x$ & $x$ \\
.70 & $x$ & $x$ & $x$ \\
.75 & $x$ & $x$ & $x$ \\
.80 & $x$ & $x$ & $x$ \\
.85 & & $x$ & $x$ \\
.90 & & & $x$ \\
\hline
\end{tabular}

tABLE IV. - COMPARSION BETWEEN WAKE SURVEY PROBE AND FORCE bALANCE THRUST AND POWER COEFFICIENTS AND EFFICIENCIES

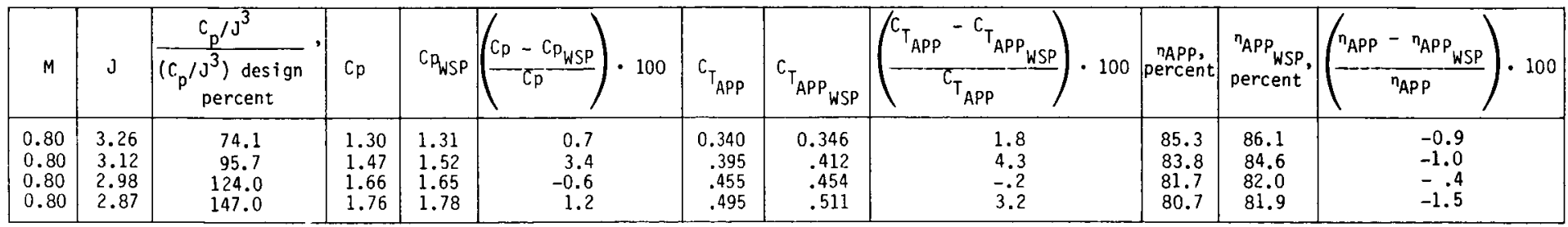




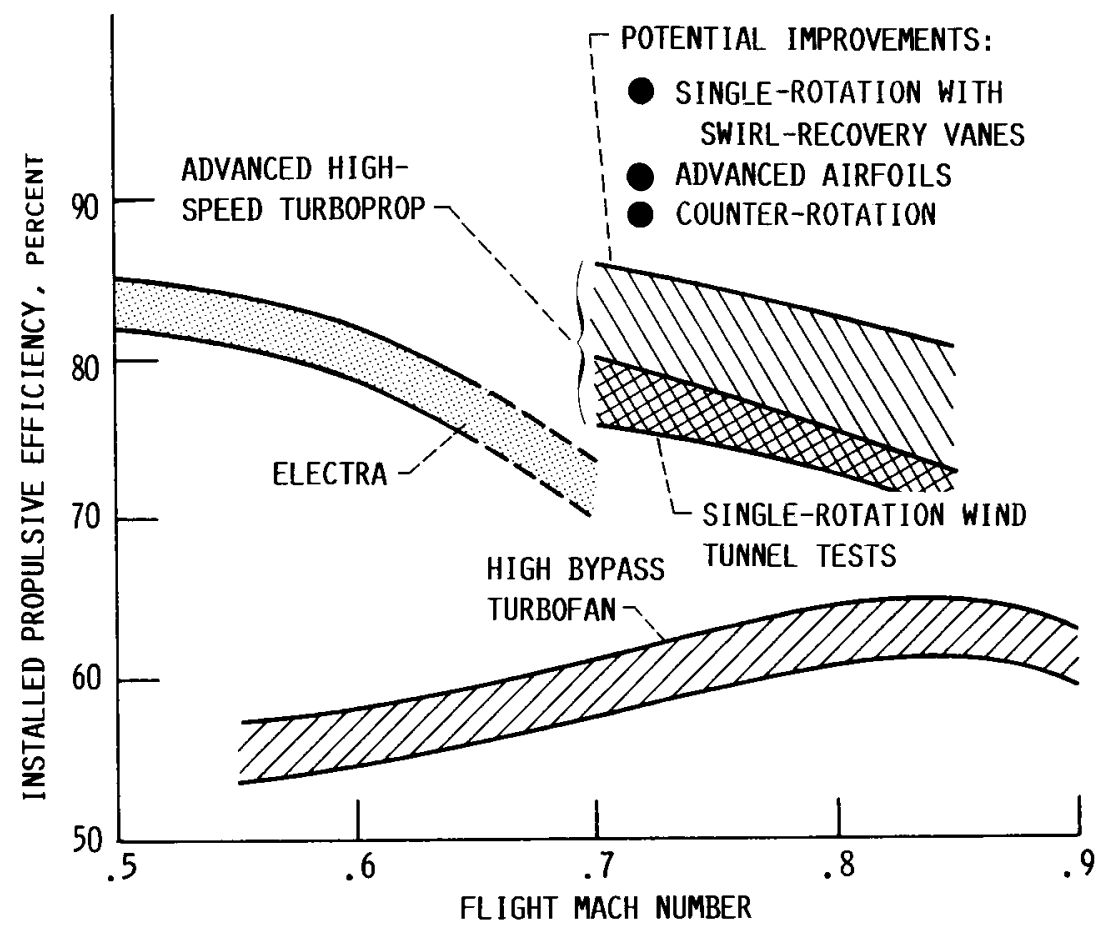

FIGURE 1. - INSTALLED PROPULSIVE EFFICIENCY TRENDS OF ADVANCED TURBOPROPS COMPARED WITH EQUIVALENT TECHNOLOGY TURBOFANS.

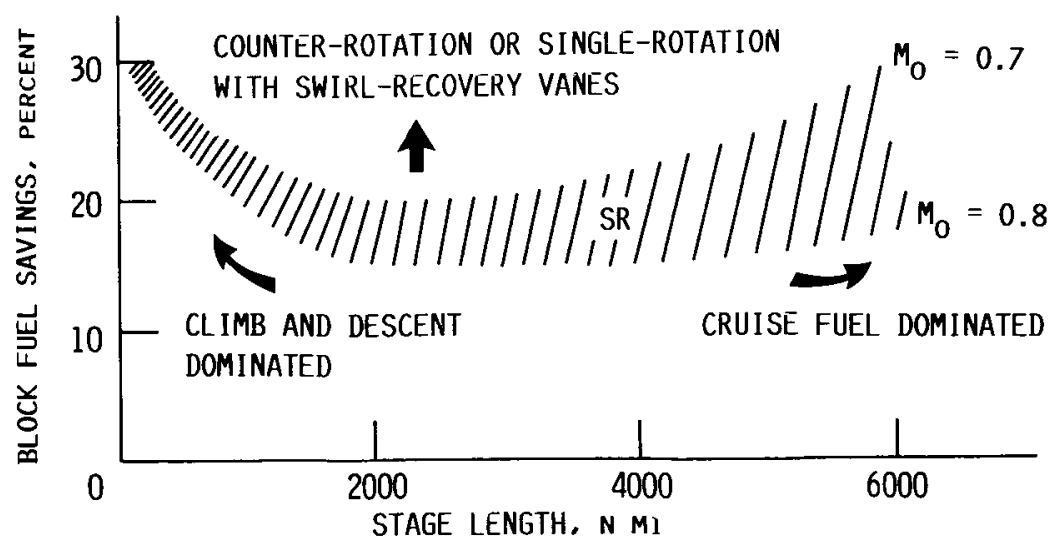

FIGURE 2. - FUEL SAVINGS TRENDS OF ADVANCED TURBOPROP AIRCRAFT OVER COMPARABLE TURBOFAN AIRCRAFT. 


\section{ORIGINAL PACE IS \\ OF POOR QUALITY}

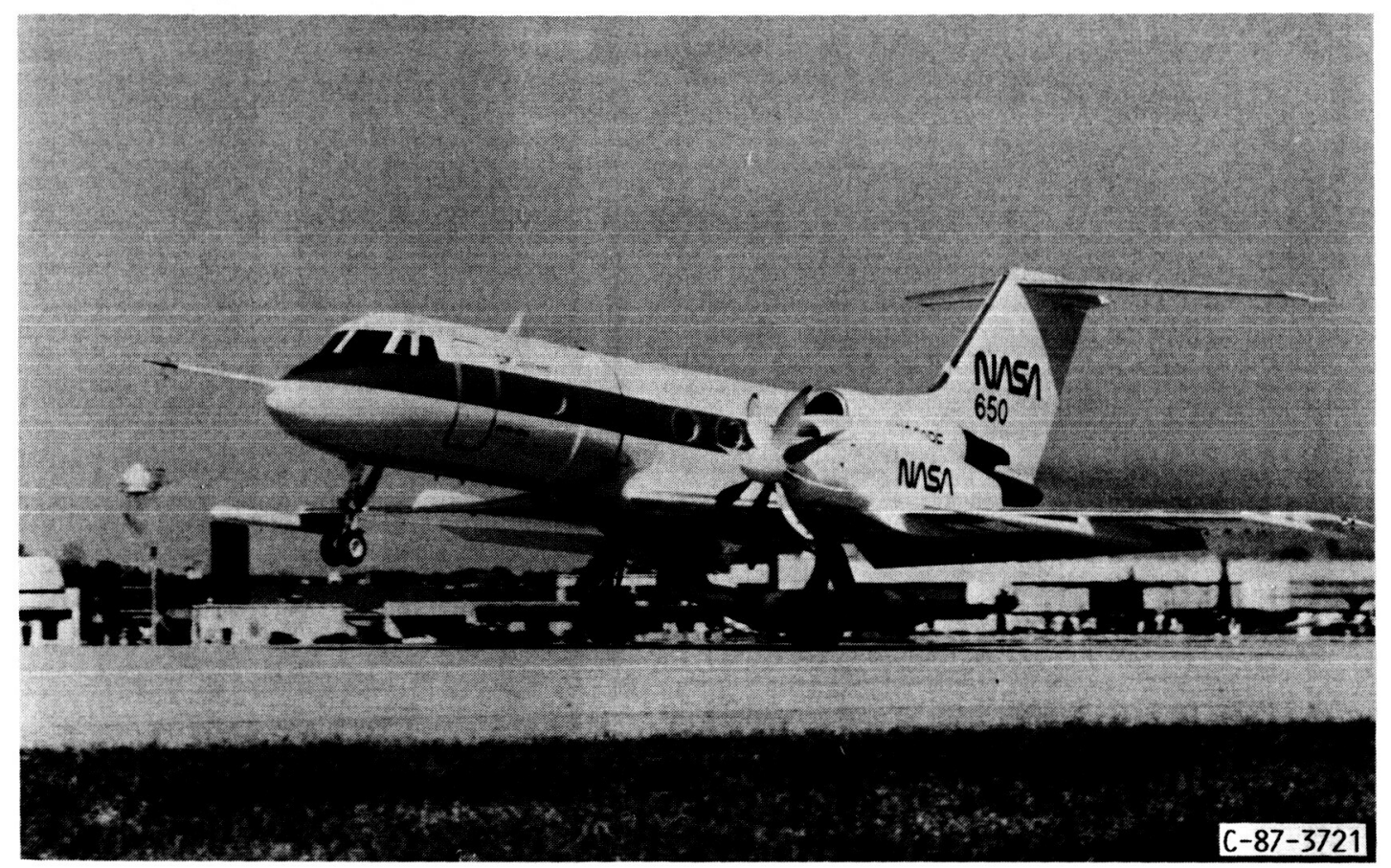

FigURE 3. - LARGE SCALE VERSION OF THE SR-7A PROP-FAN ON THE GULFSTREAM II AIRPLANE. 


\section{ORIGINAL PAOE IS \\ OF POOR QUALTTY}

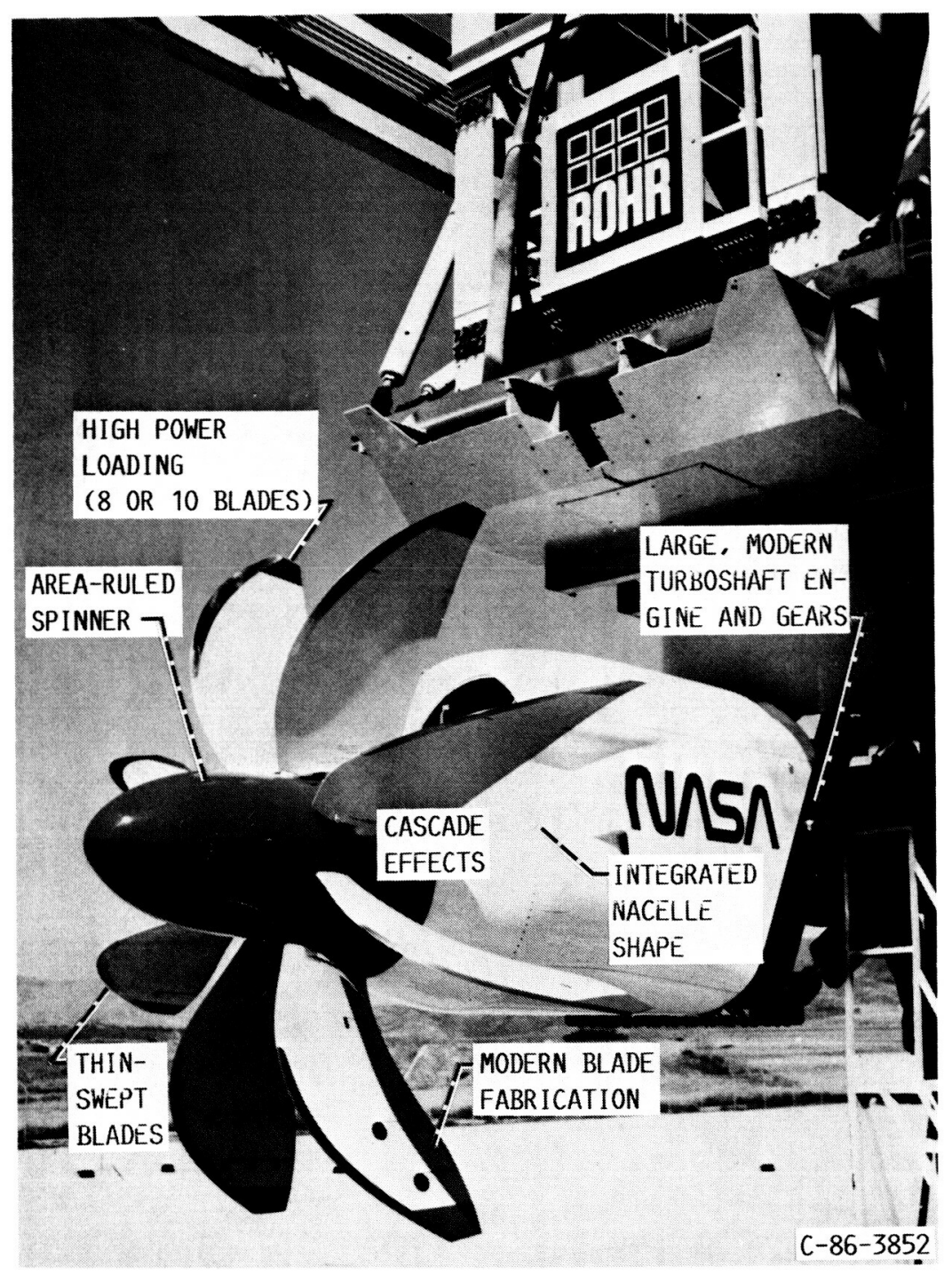

FIGURE 4. - AERODYNAMIC DESIGN CONCEPTS FOR AN ADVANCED HIGHSPEED TURBOPROP PROPULSION SYSTEM. 

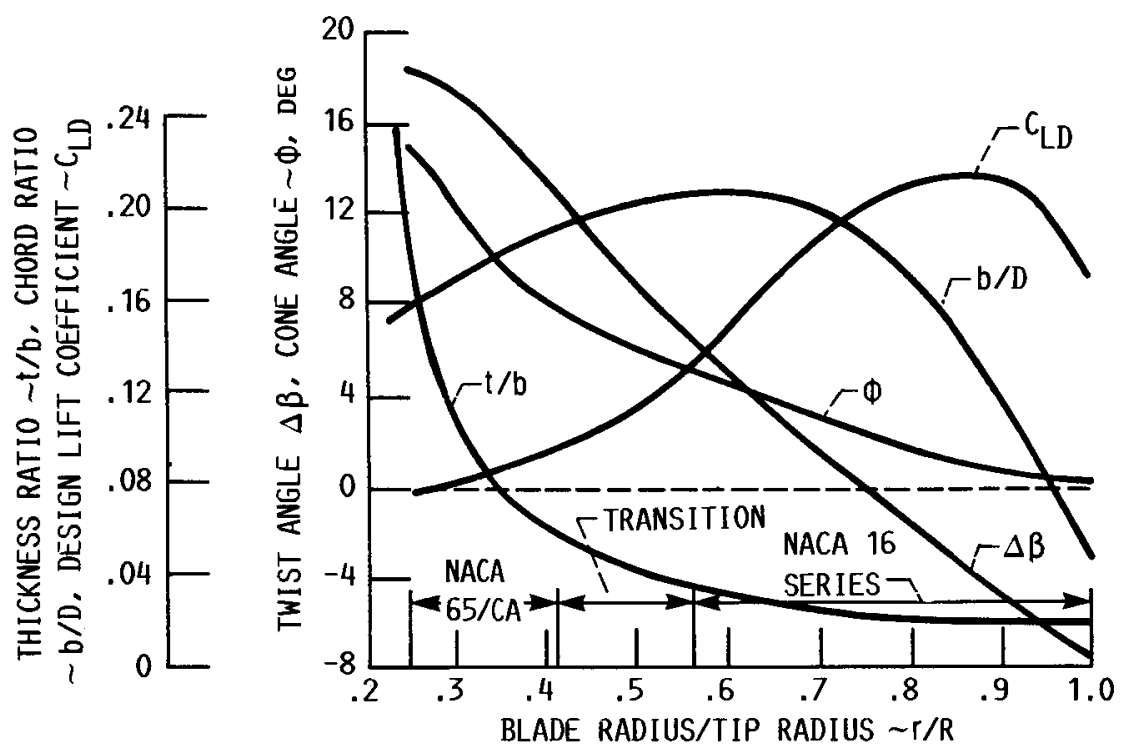

FIGURE 5. - VARIATION OF PROPELLER DESIGN PARAMETERS WITH BLADE RADIUS FOR $41^{\circ}$ SWEPT SR-7A PROPELLER. NUMBER OF BLADES, 8; BLADE ACTIVITY FACTOR AF $=227$; INTEGRATED DESIGN LIFT COEFFICIENT $C_{L i}=0.202 ;$ DIAMETER, $0.62 \mathrm{M}$ (24.50 IN.). BLADE CHARACTERISTICS ARE SHOWN FOR THE DEFLECTED BLADE POSITION AT THE DESIGN/CRUISE CONDITION. 
ORIGINAL PRCE IS

OF. POOR QUALTY

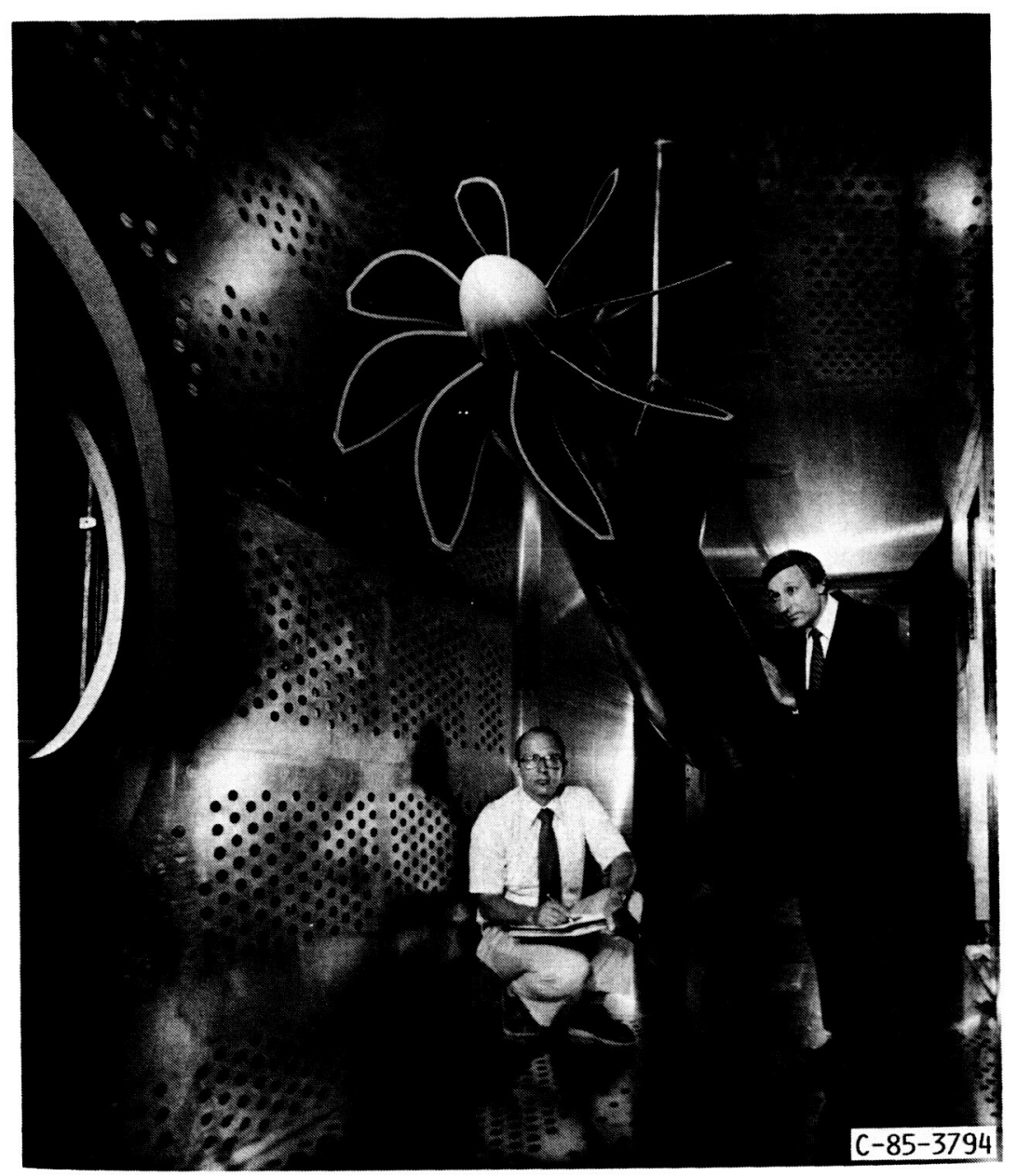

FIGURE 6. - THE SR-7A PROP-FAN INSTALLED IN THE NASA LEWIS 8- BY 6-FOOT WIND TUNNEL. 


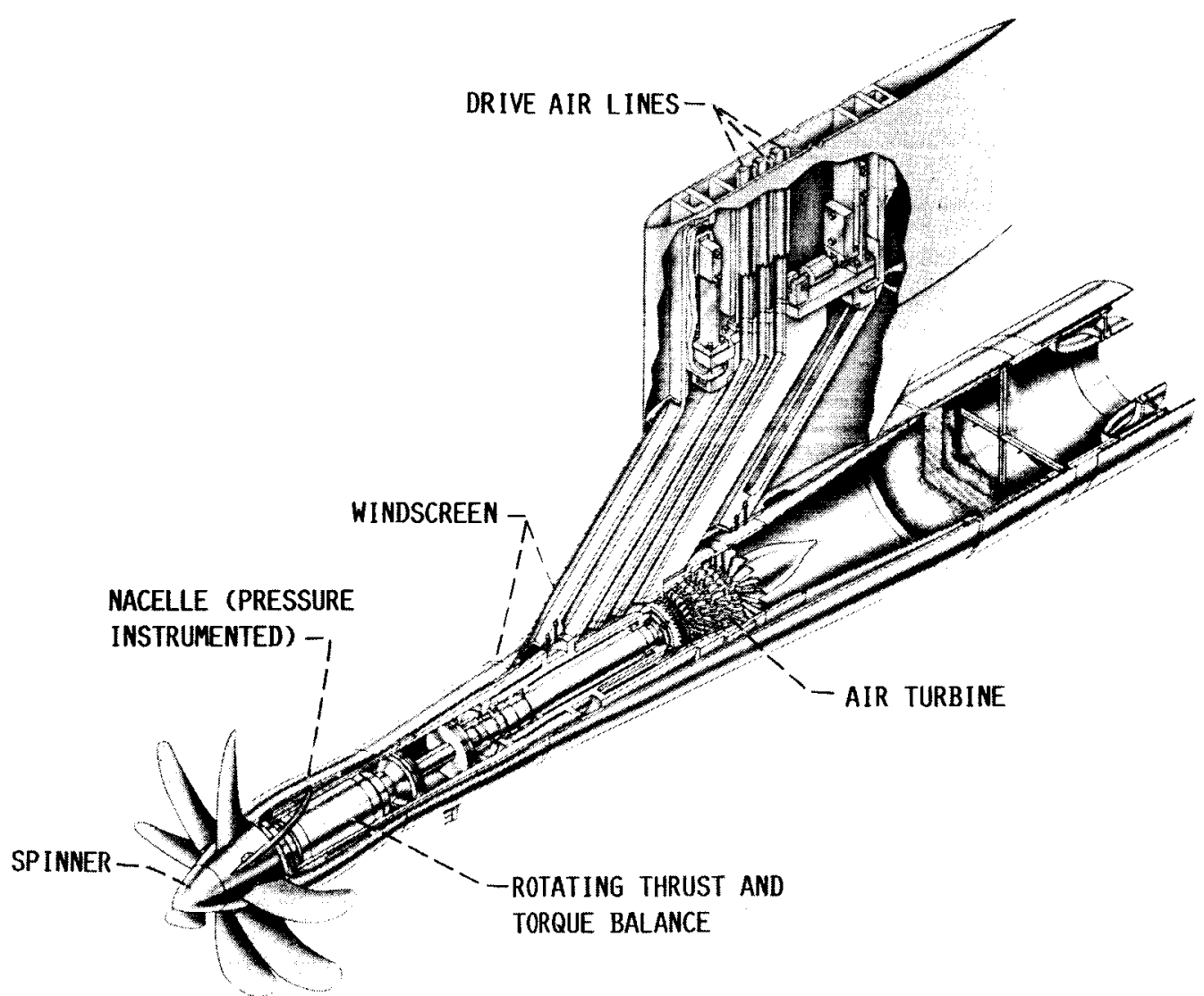

FIGURE 7. - CUTAWAY VIEW OF THE LEWIS 746 kW (1000 HP) PROPELLER TEST RIG. 


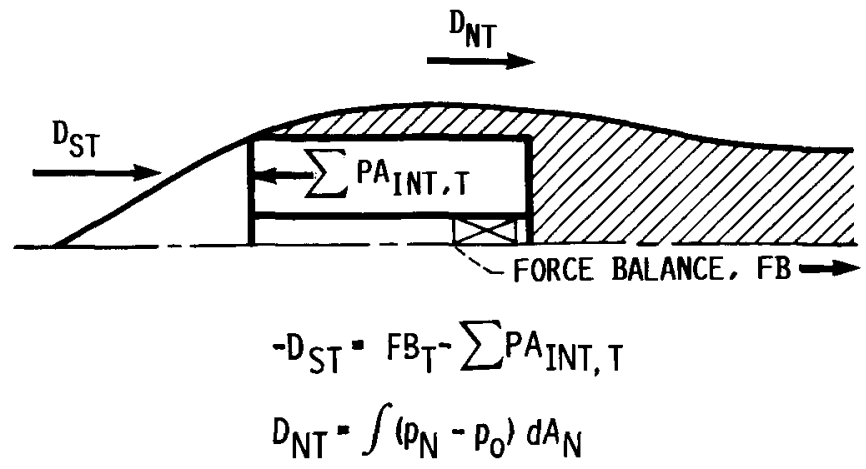

(A) FORCES ACTING ON BALANCE DURING TARE RUNS.

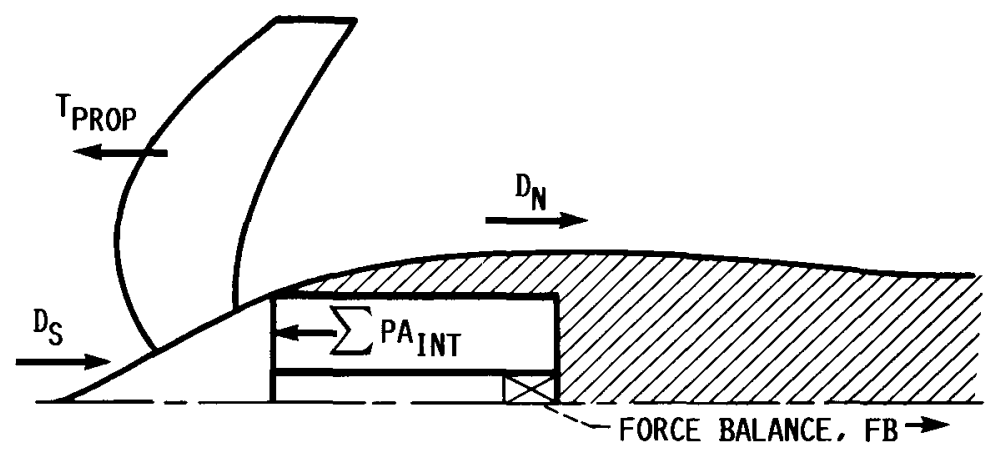

(B) FORCES ACTING ON BALANCE DURING TEST RUNS.

FIGURE 8. - FORCES ACTING ON BALANCE DURING TARE AND TEST RUNS.

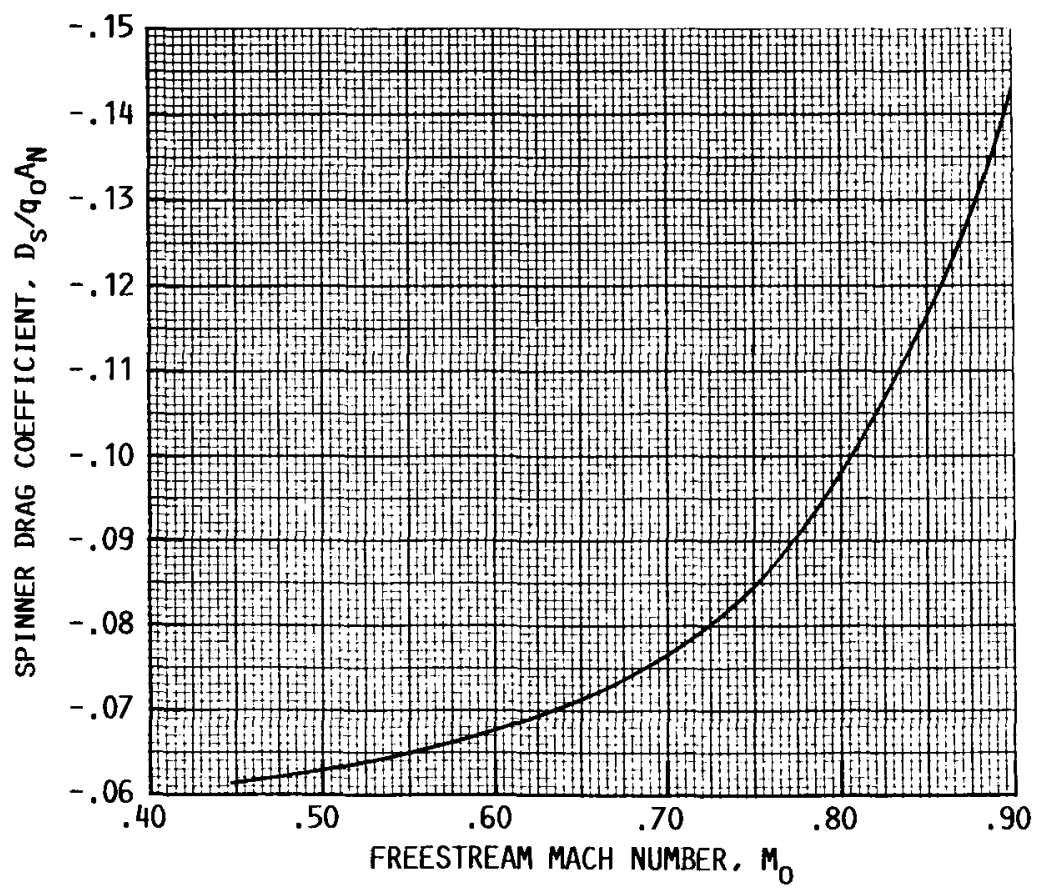

FIGURE 9. - SR-7A SPINNER DRAG COEFFICIENT VERSUS MACH NUMBER. 

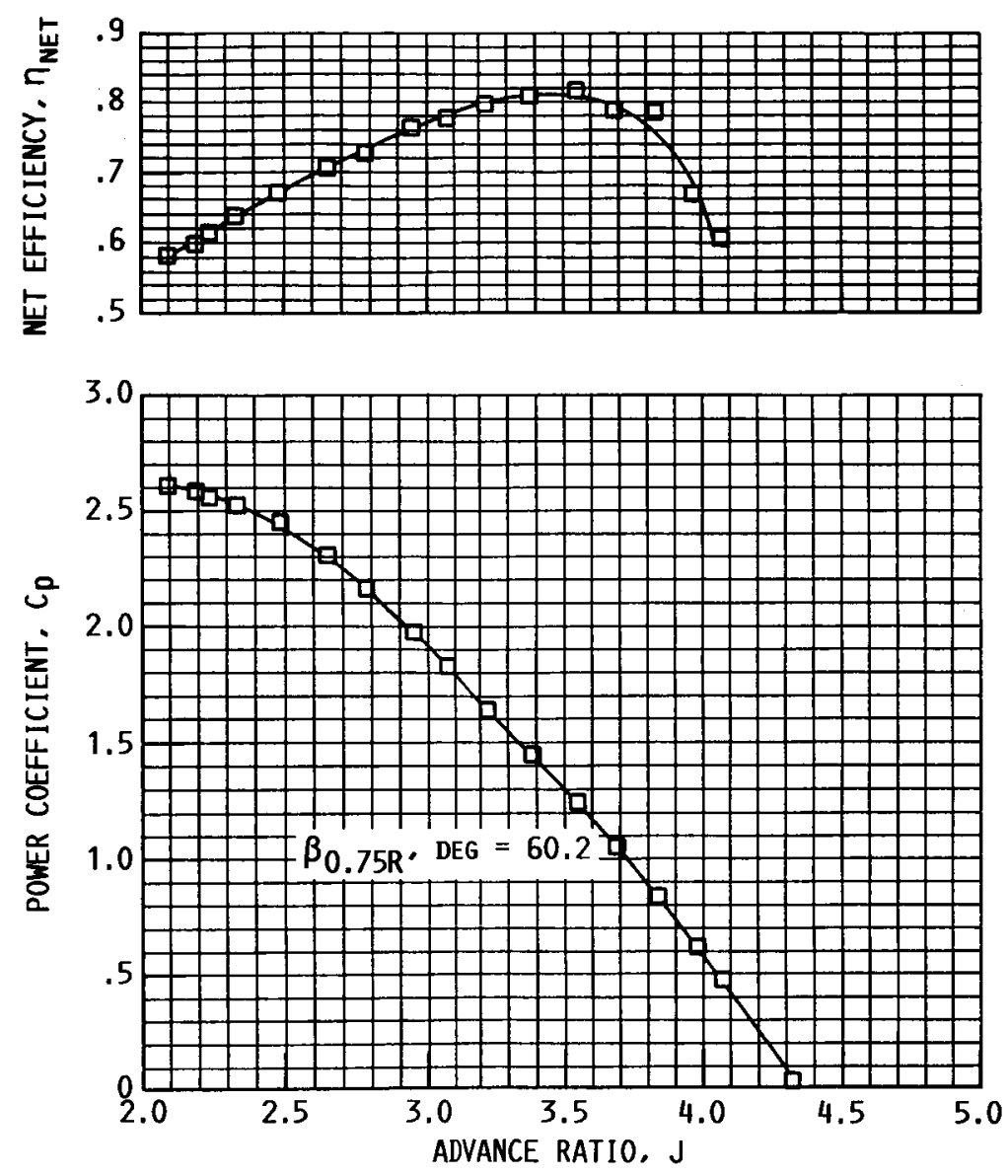

FIGURE 10. - SR-7A PERFORMANCE AT MACH NUMBER 0.45. 

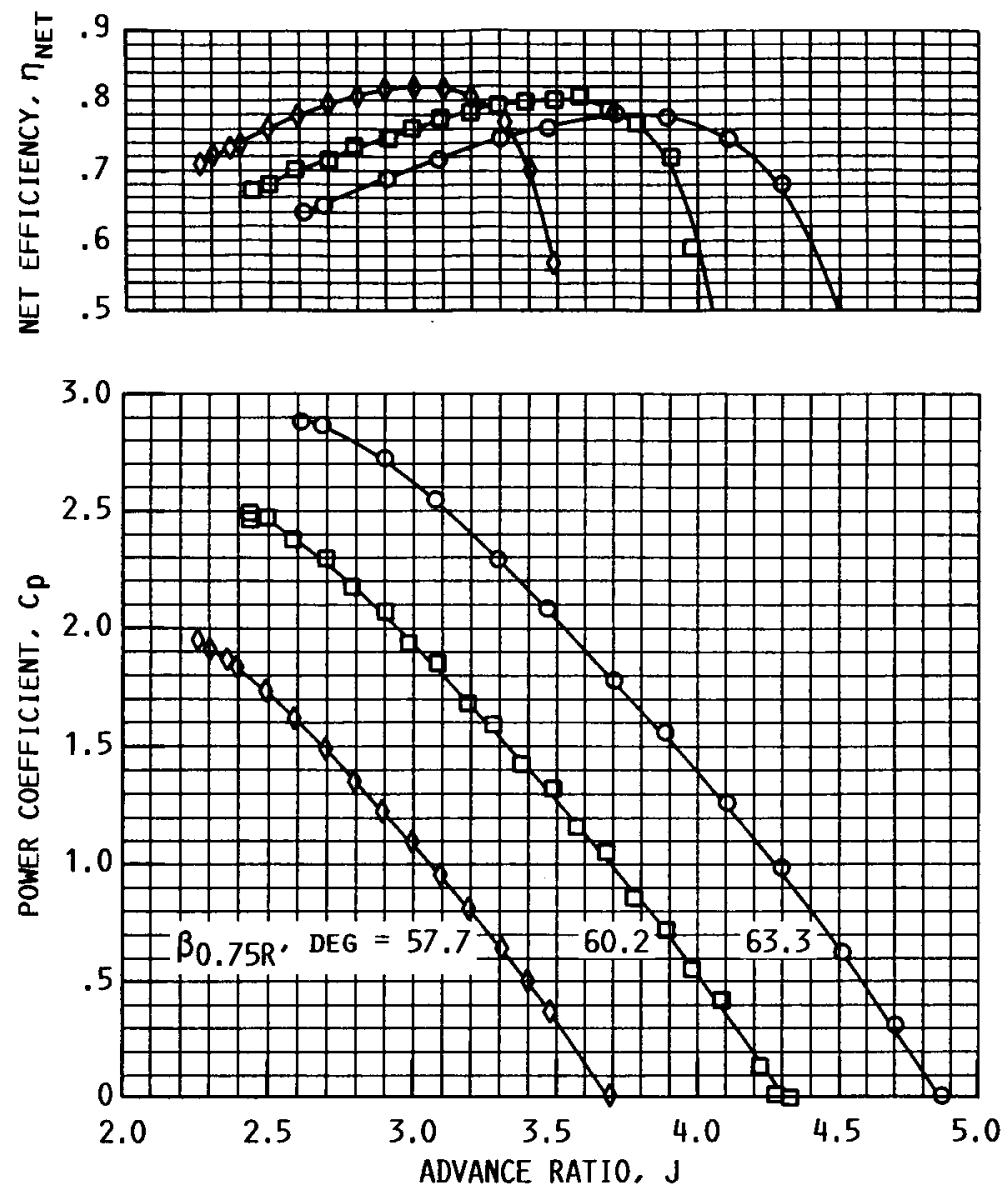

FIGURE 11. - SR-7A PERFORMANCE AT MACH NUMBER 0.60. 

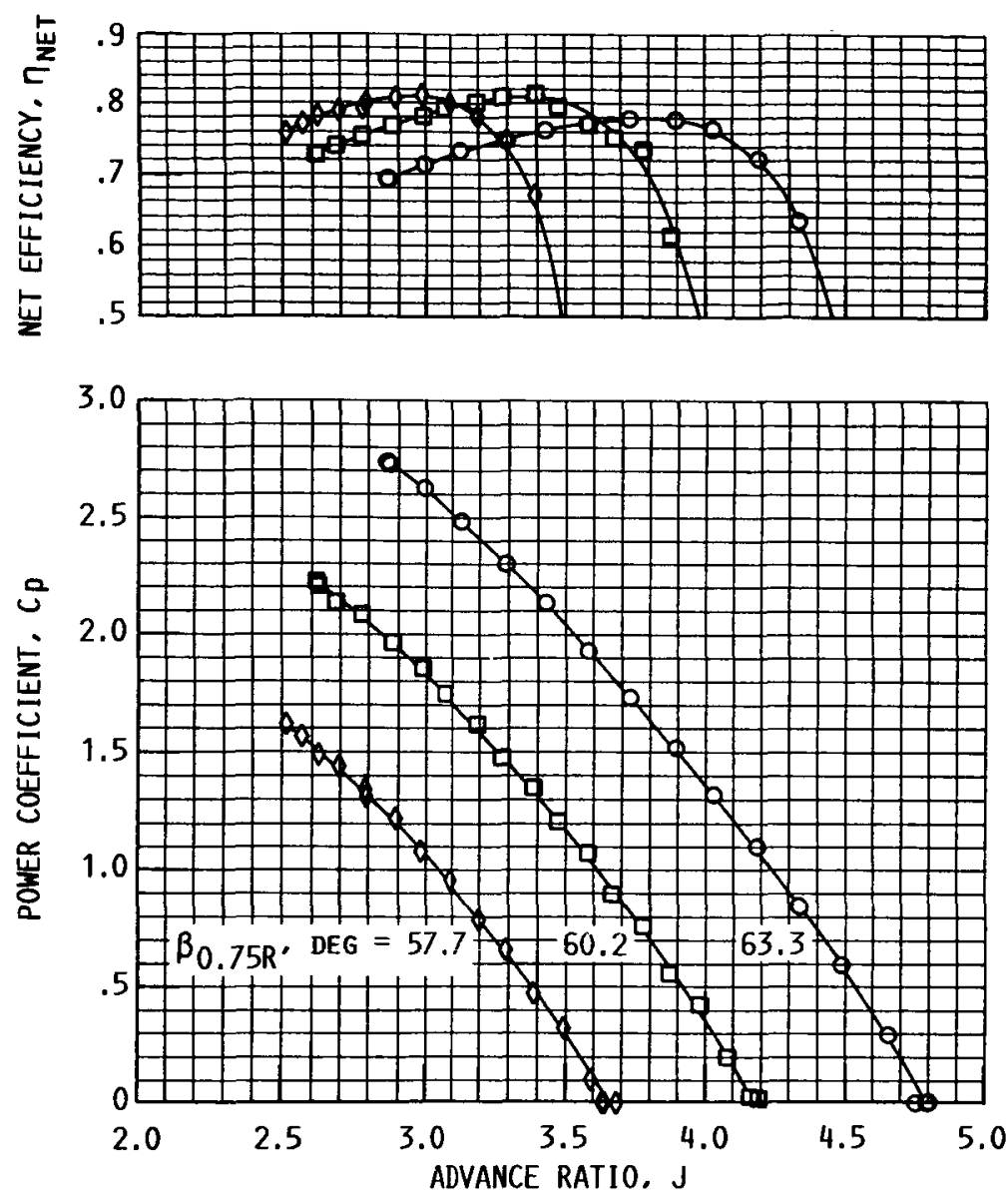

FIGURE 12. - SR-7A PERFORMANCE AT MACH NUMBER 0.70 . 

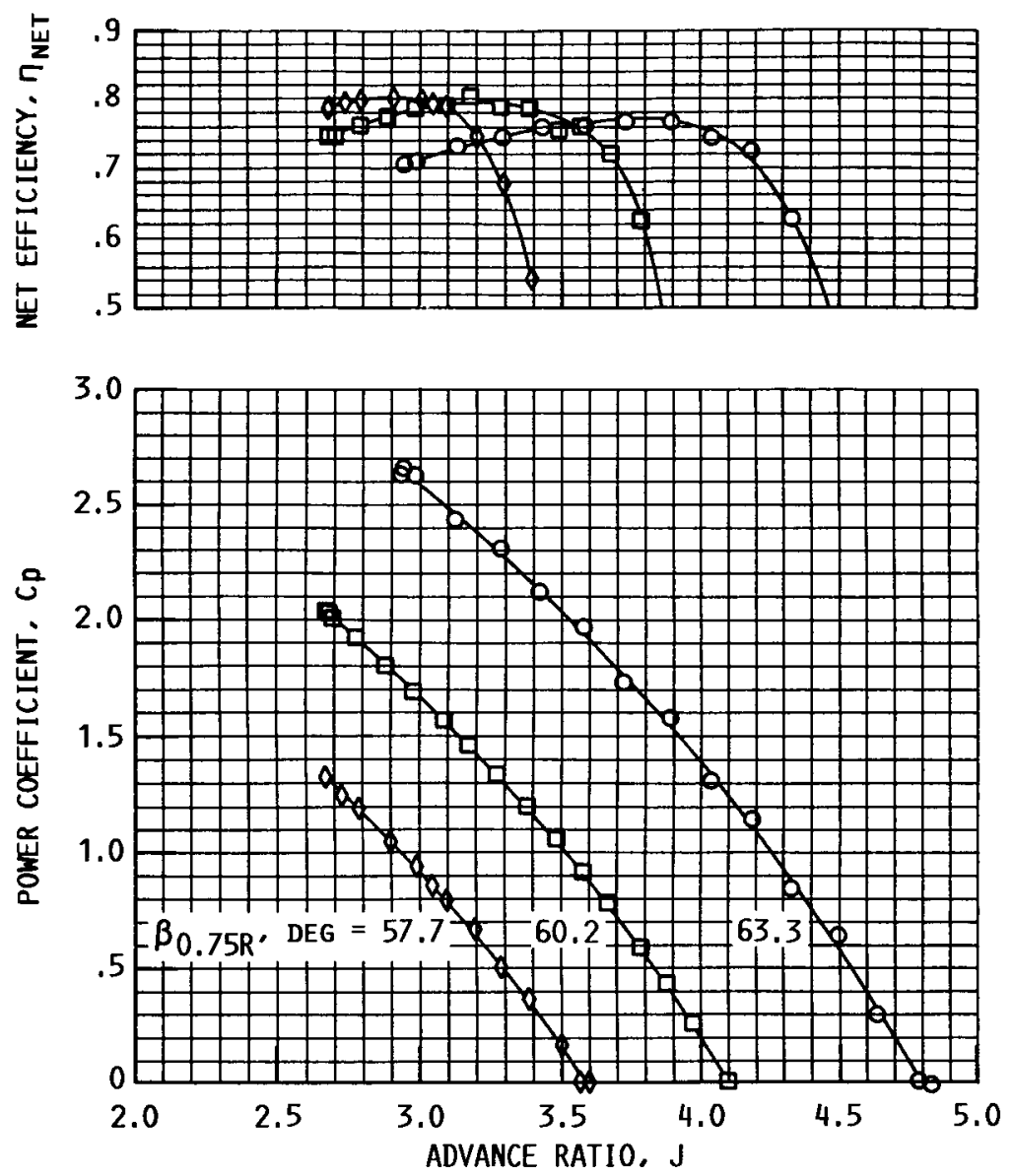

FIGURE 13. - SR-7A PERFORMANCE AT MACH NUMBER 0.75. 

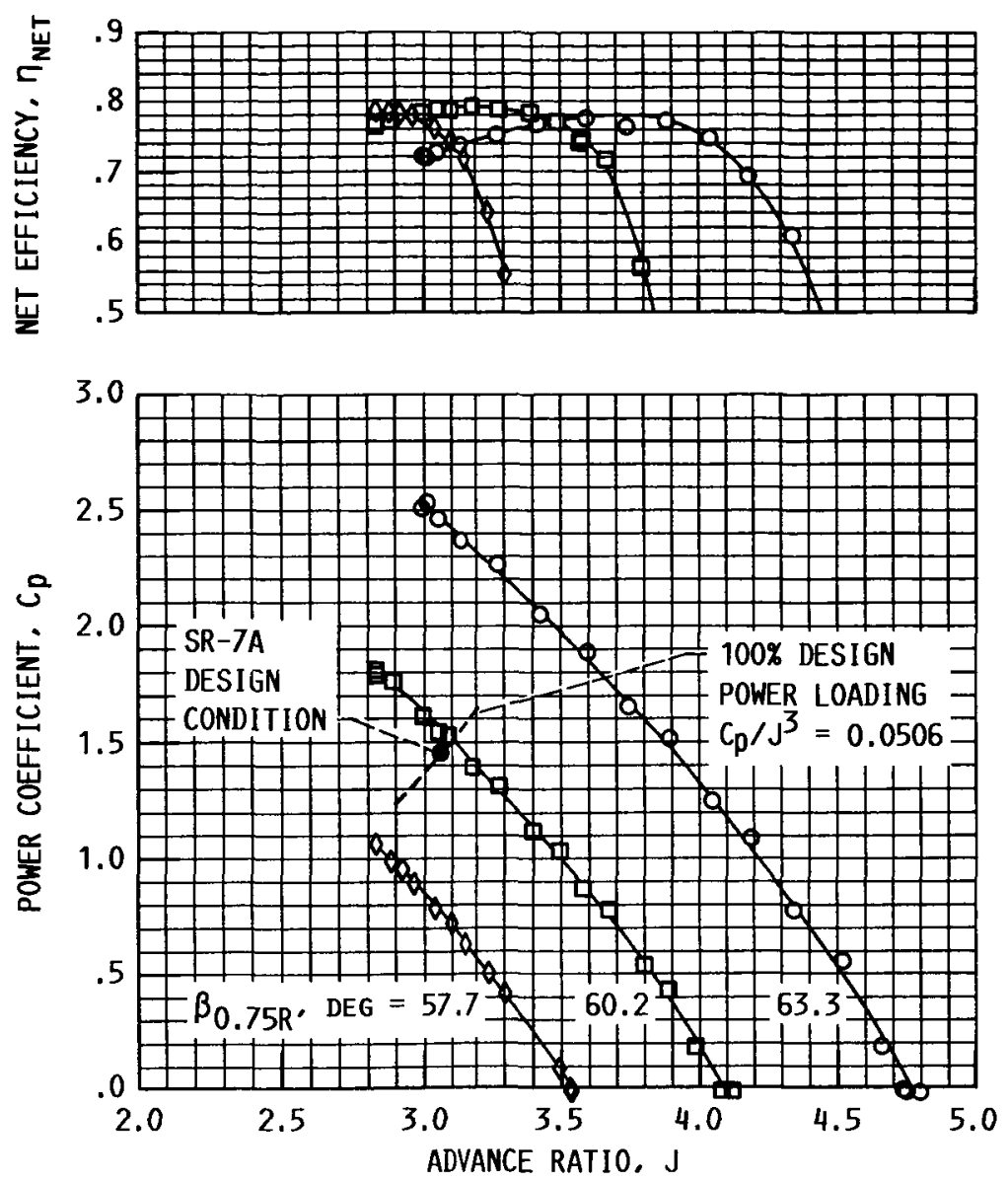

FIGURE 14. - SR-7A PERFORMANCE AT MACH NUMBER 0.80. 

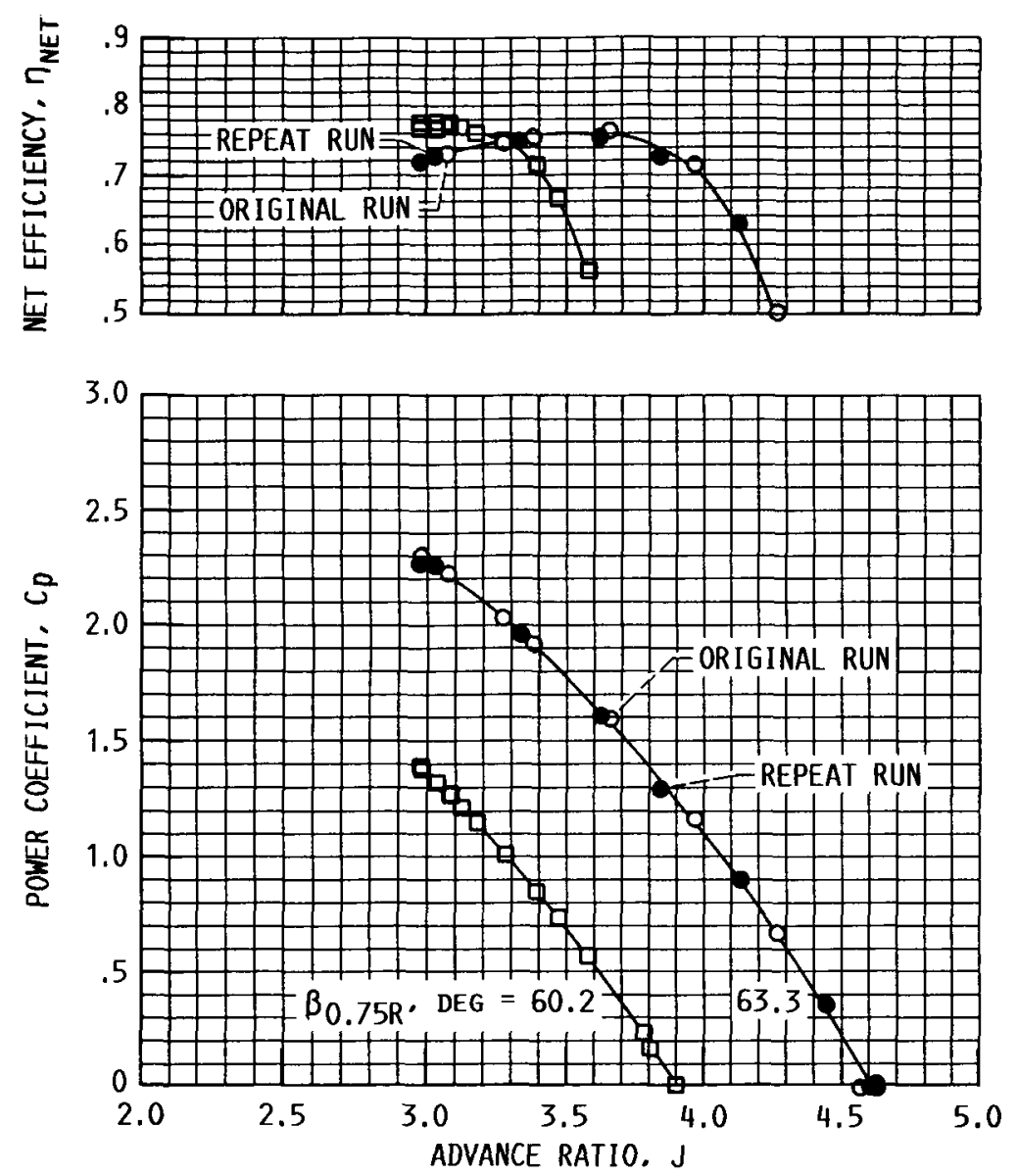

FIGURE 15. - SR-7A PERFORMANCE AT MACH NUMBER 0.85 . 

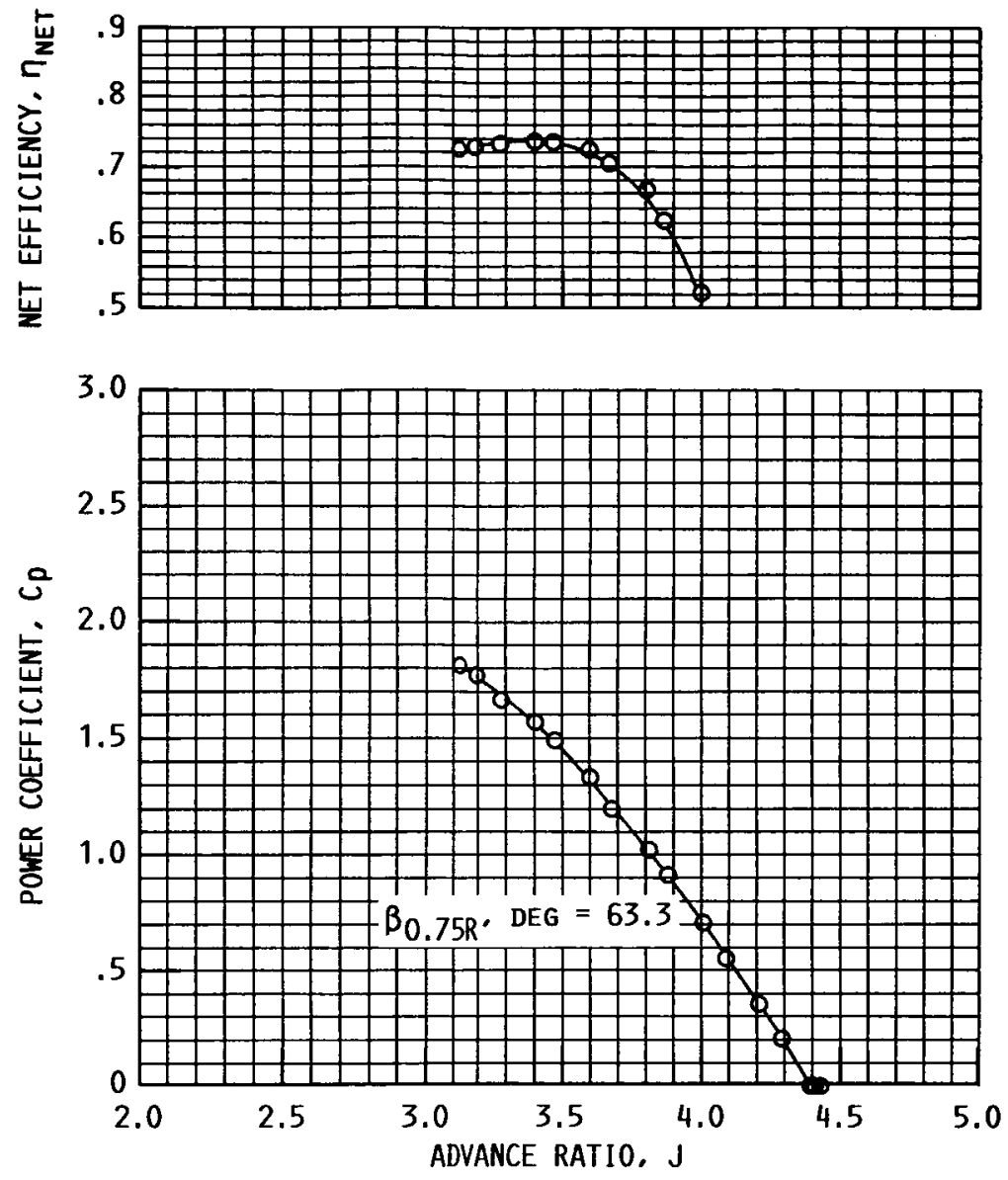

FIGURE 16. - SR-7A PERFORMANCE AT MACH NUMBER 0.90. 


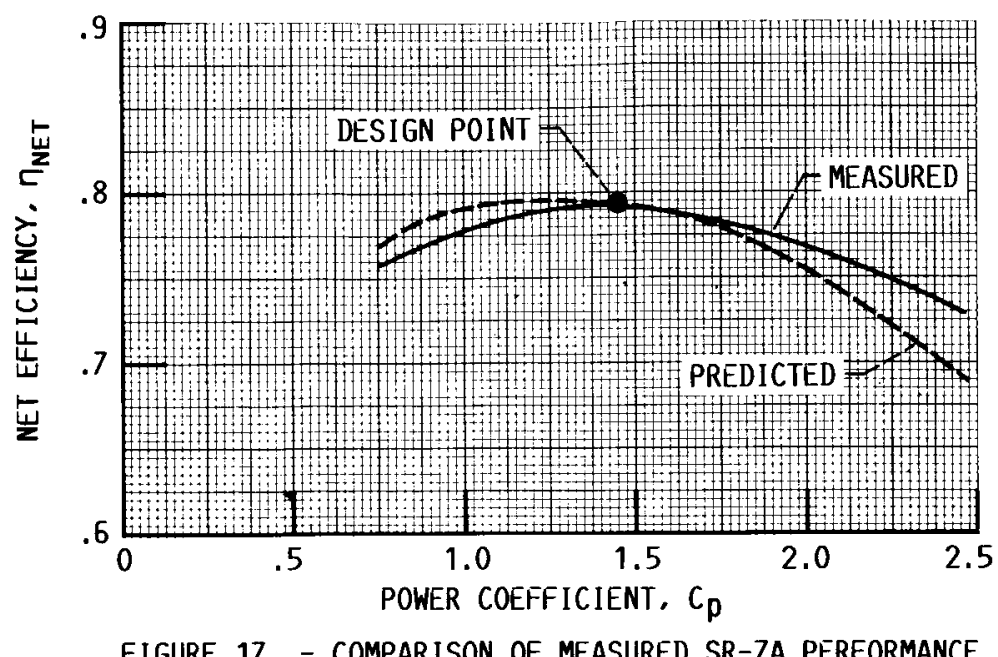

FIGURE 17. - COMPARISON OF MEASURED SR-7A PERFORMANCE AT THE DESIGN MACH NUMBER OF 0.80 AND THE DESIGN ADVANCE RATIO OF 3.06 .

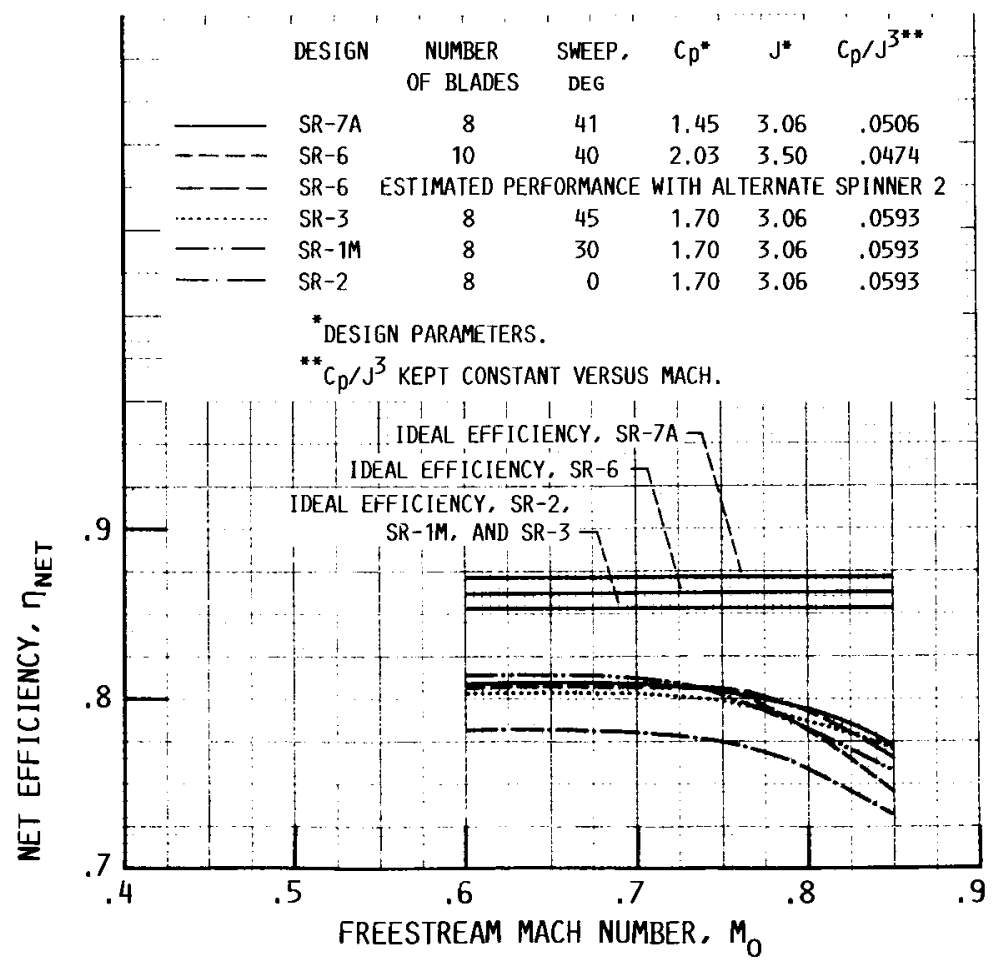

FIGURE 18. - COMPARISON OF IDEAL TO ACTUAL MEASURED EFFICIENCY VERSUS FREESTREAM MACH NUMBER FOR SEVERAL PROP-FANS. 

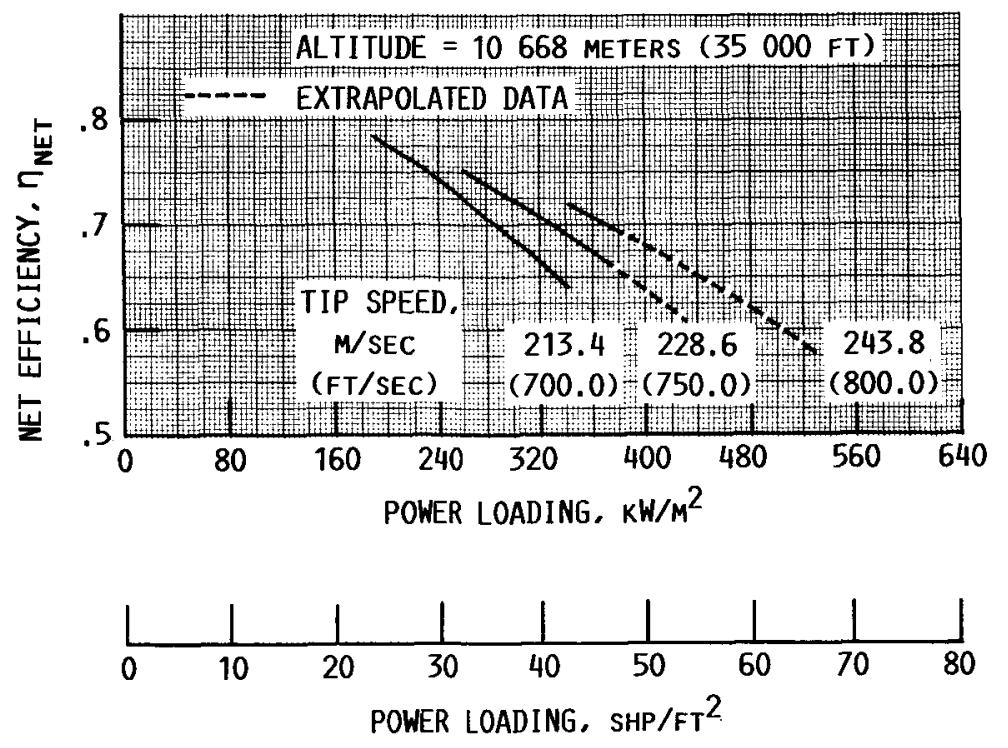

FIGURE 19. - VARIATION OF SR-7A NET EFFICIENCY WITH POWER LOADING AND TIP SPEED AT A MACH NUMBER OF 0.60 .

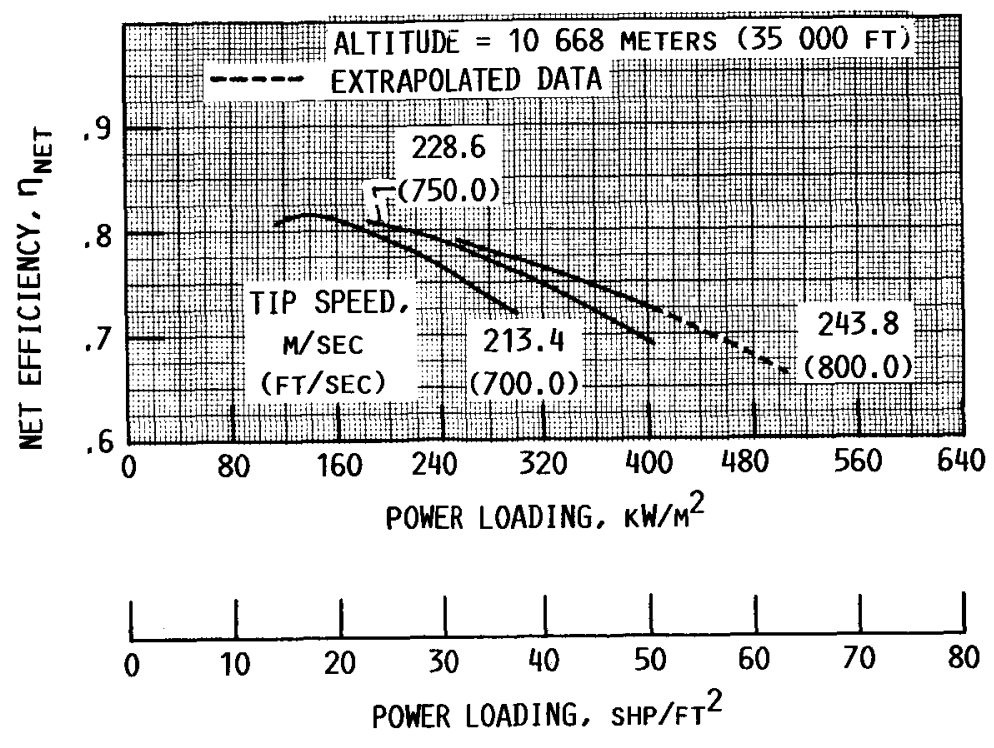

FIGURE 20. - VARIATION OF SR-7A NET EFFICIENCY WITH POWER LOADING AND TIP SPEED AT A MACH NUMBER OF 0.70 . 

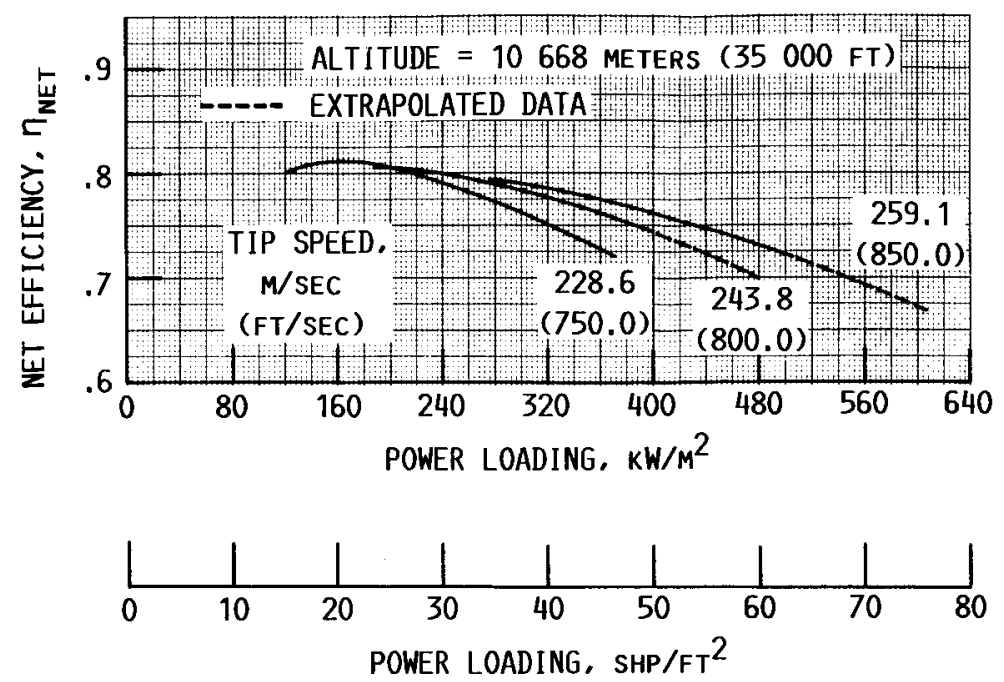

FIGURE 21. - VARIATION OF SR-7A NET EFFICIENCY WITH POWER LOADING AND TIP SPEED AT A MACH NUMBER OF 0.75 .

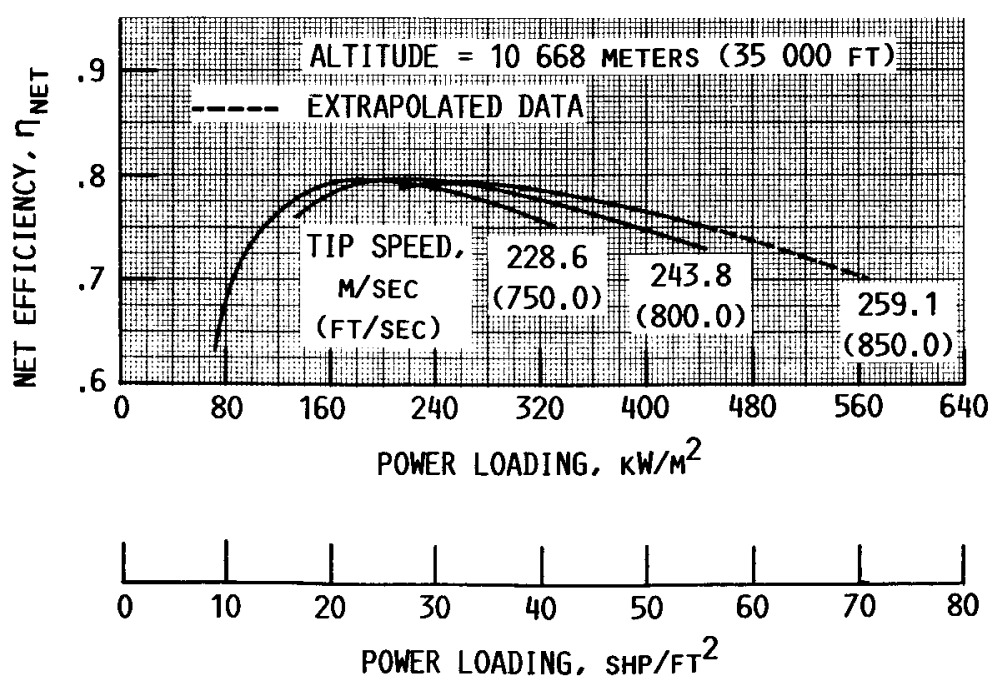

FIGURE 22. - VARIATION OF SR-7A NET EFFICIENCY WITH POWER LOADING AND TIP SPEED AT A MACH NUMNBER OF 0.80 . 


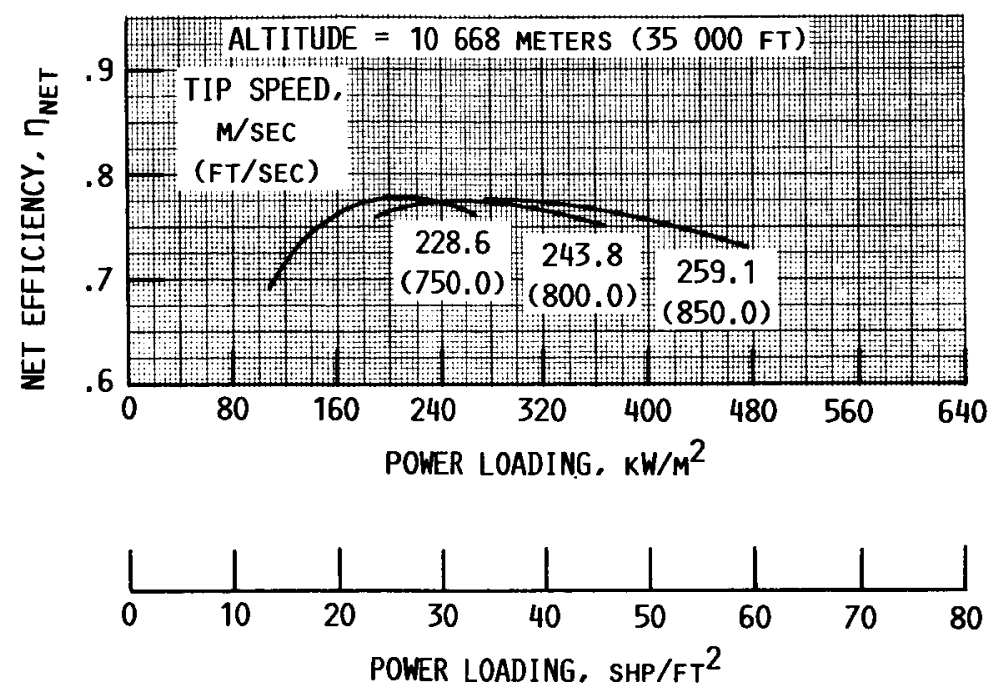

FIGURE 23. - VARIATION OF SR-7A NET EFFICIENCY WITH POWER LOADING AND TIP SPEED AT A MACH NUMBER OF 0.85 .

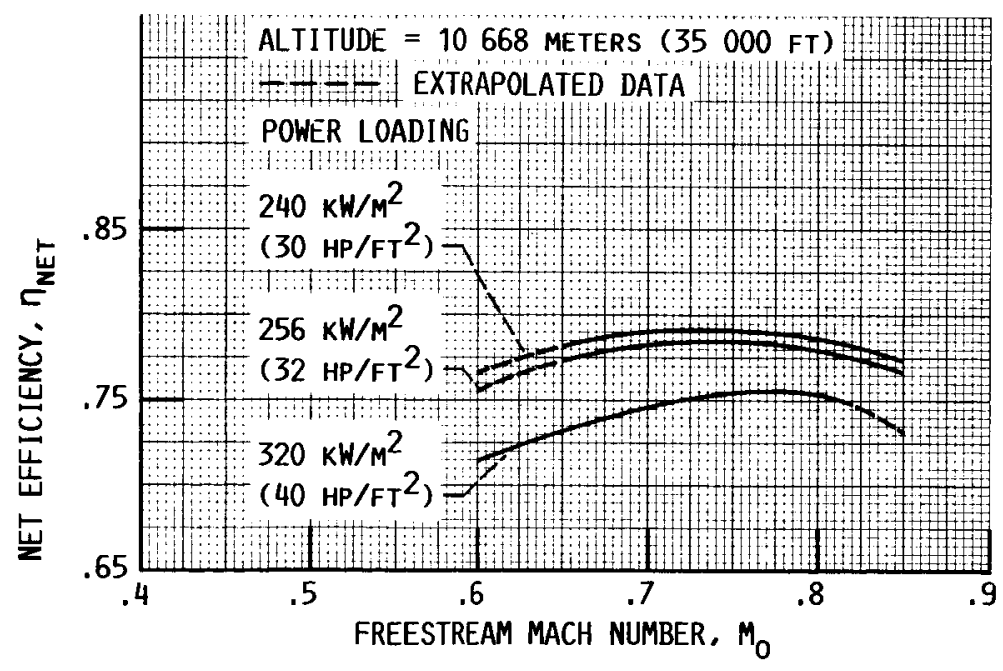

FIGURE 24. - VARIATION OF SR-7A NET EFFICIENCY WITH MACH NUMBER AND POWER LOADING AT A TIP SPEED OF $228.6 \mathrm{M} / \mathrm{SEC}(750.0 \mathrm{FT} / \mathrm{SEC})$. 


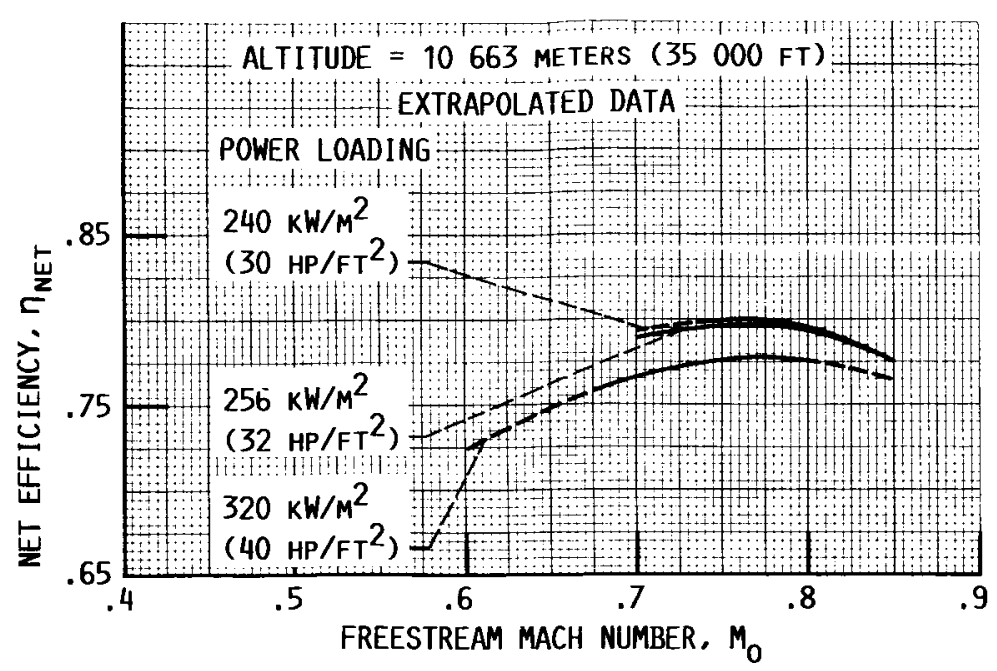

FIGURE 25. - VARIATION OF SR-7A NET EFFICIENCY WITH MACH NUMBER AND POWER LOADING AT A TIP SPEED OF $243.8 \mathrm{M} / \mathrm{SEC}(800.0 \mathrm{FT} / \mathrm{SEC})$.

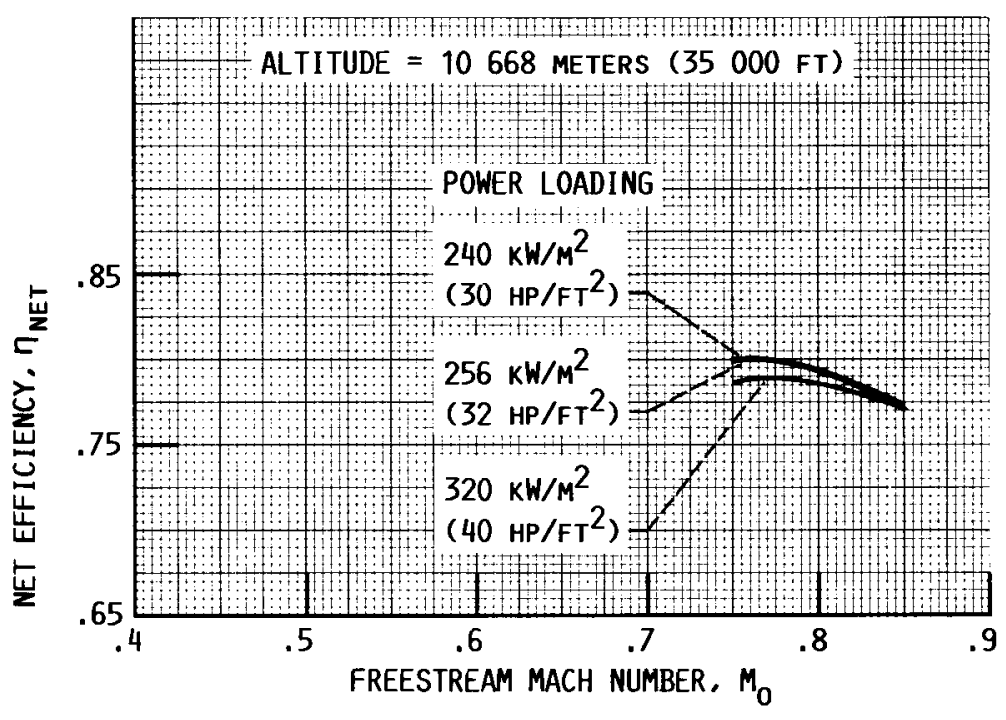

FIGURE 26. - VARIATION OF SR-7A NET EFFICIENCY WITH MACH NUMBER AND POWER LOADING AT A TIP SPEED OF $259.1 \mathrm{M} / \mathrm{SEC}(850.0 \mathrm{FT} / \mathrm{SEC})$. 


\section{ORIGTNAL PAOE IS \\ OF POOR QUALITY}

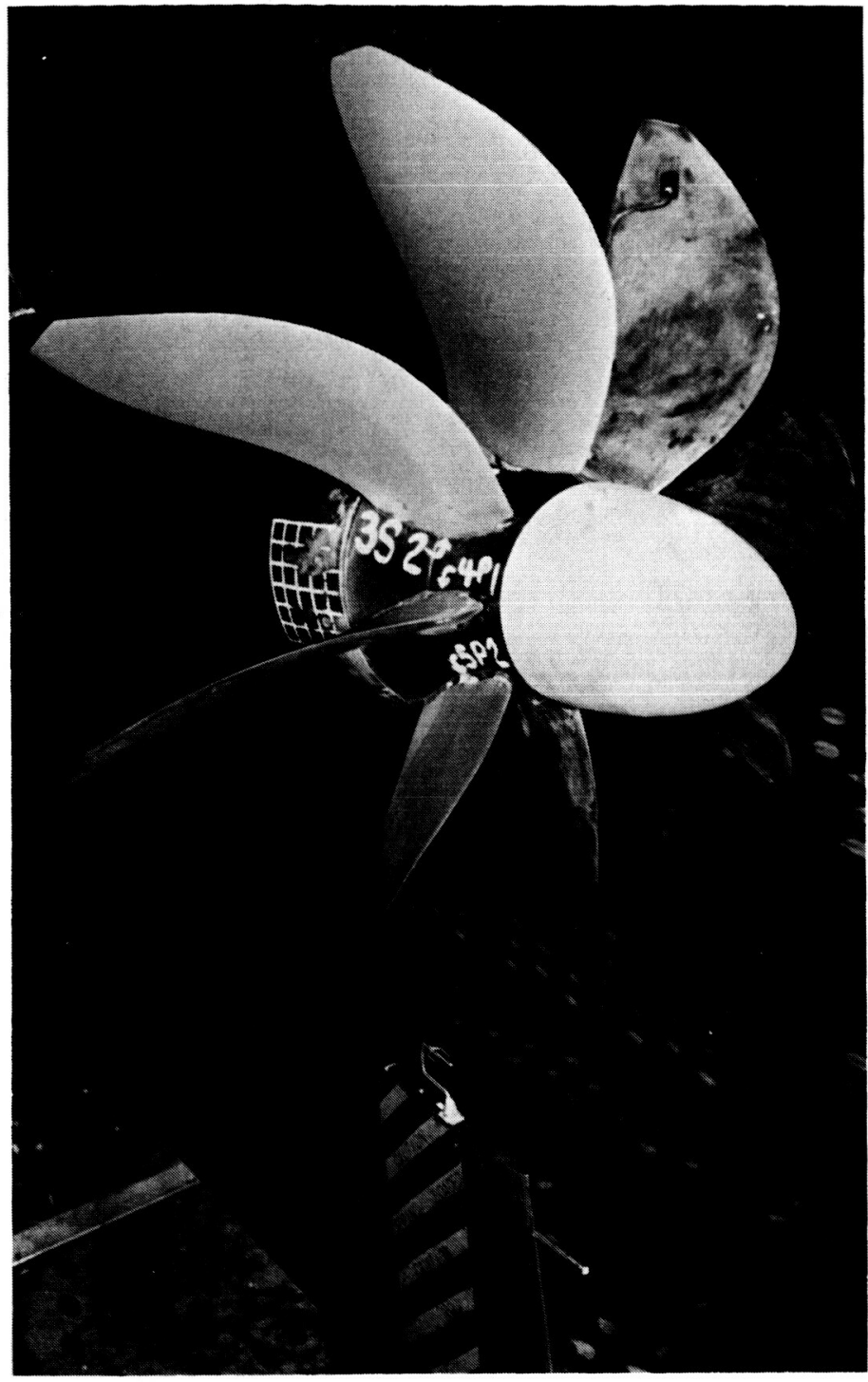

FIGURE 27. - PHOTO SHOWING THE SURVEY PROBE AND SUPPORT STRUT MOUNTED FROM THE WIND TUNNEL FLOOR. 
DTCYNAL PACE IS

OF. POOR QUALITY

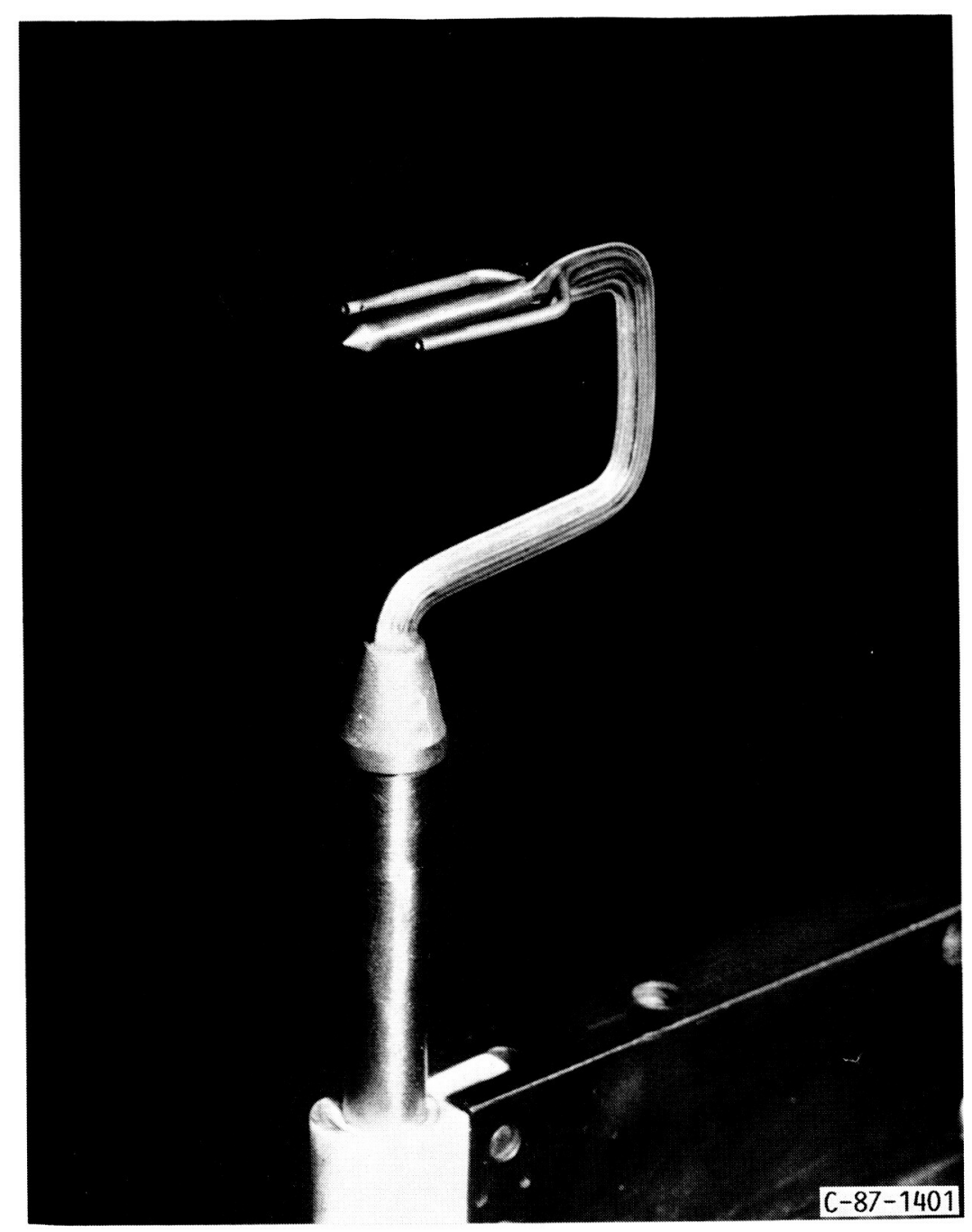

FIGURE 28. - CLOSE-UP VIEW OF THE WAKE SURVEY PROBE. 


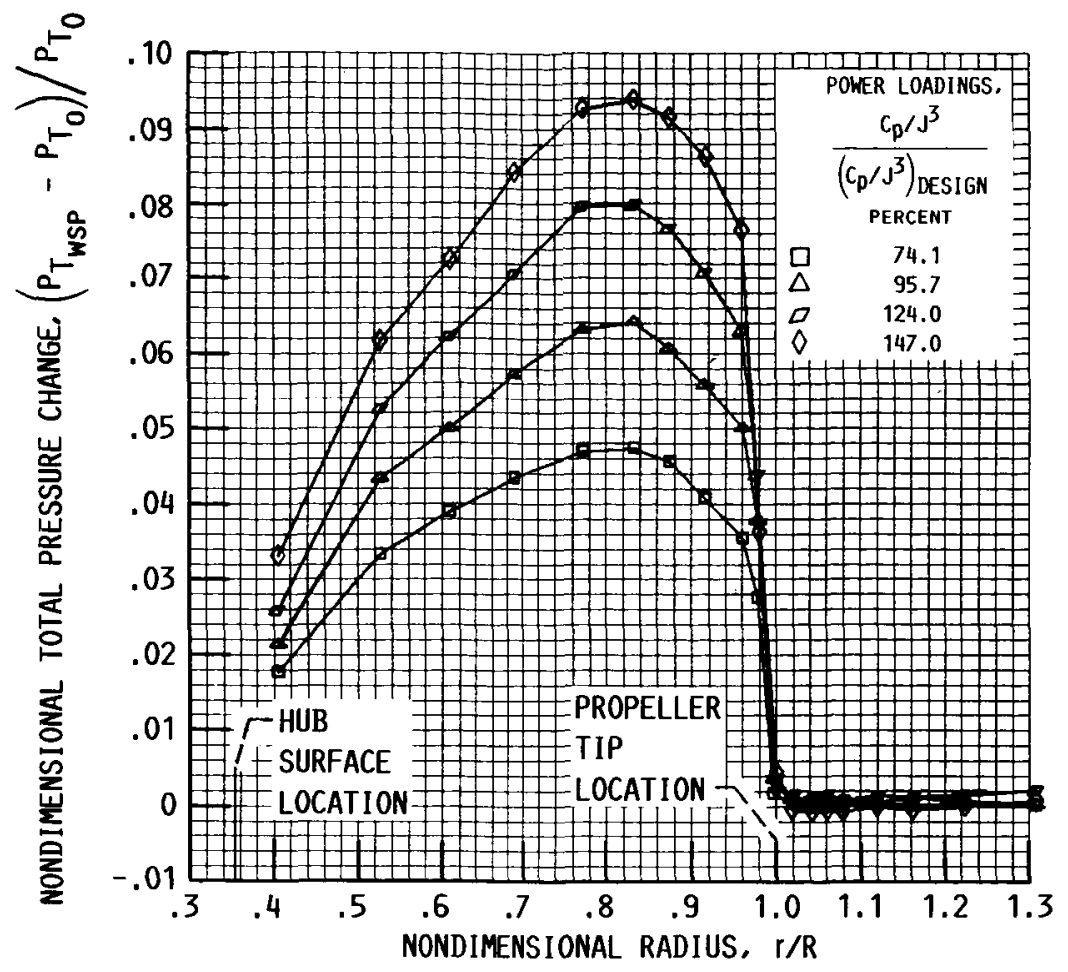

FIGURE 29. - COMPARISON OF NONDIMENSIONAL TOTAL PRESSURE DISTRIBUTIONS AT DIFFERENT POWER LOADINGS. $M=0.80, \beta_{0.75 R}=60.2^{\circ}$.

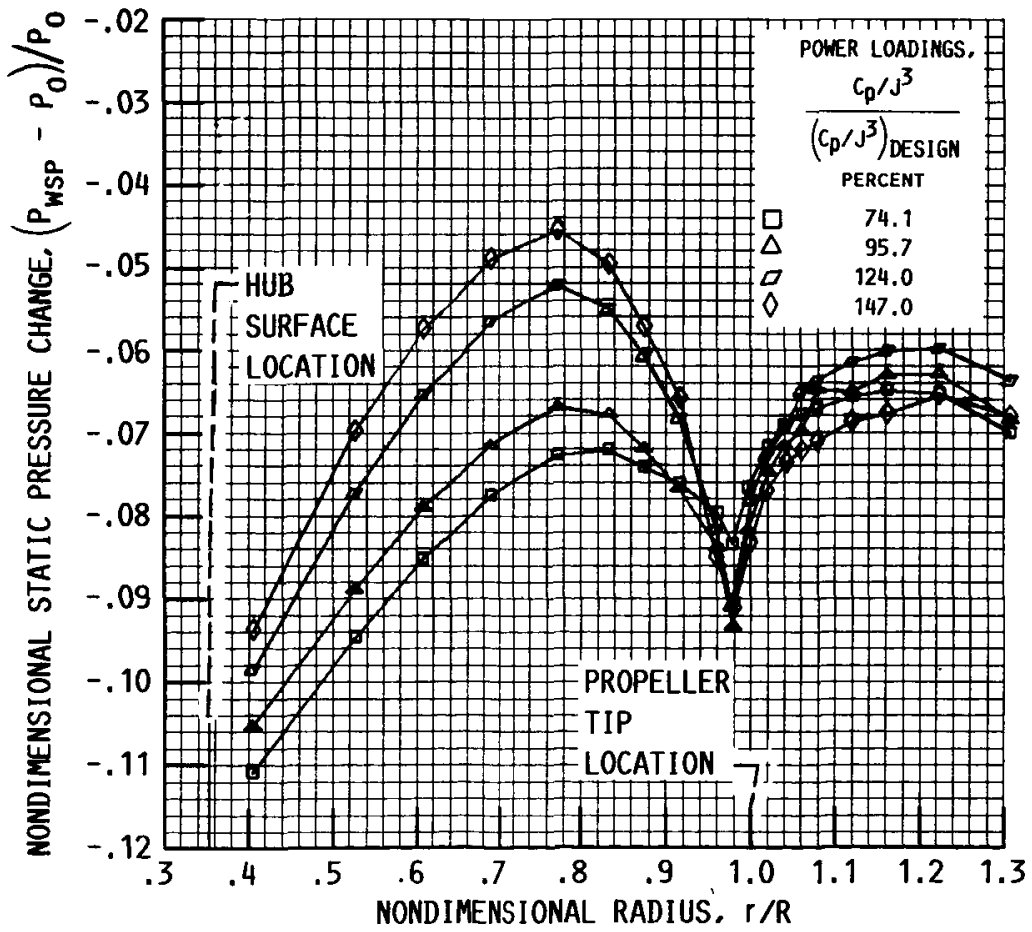

FIGURE 30. - COMPARISON OF NONDIMENSIONAL STATIC PRESSURE DISTRIBUTIONS AT DIFFERENT POWER LOADINGS. $M=0.80, \beta_{0.75 R}=60.2^{\circ}$. 


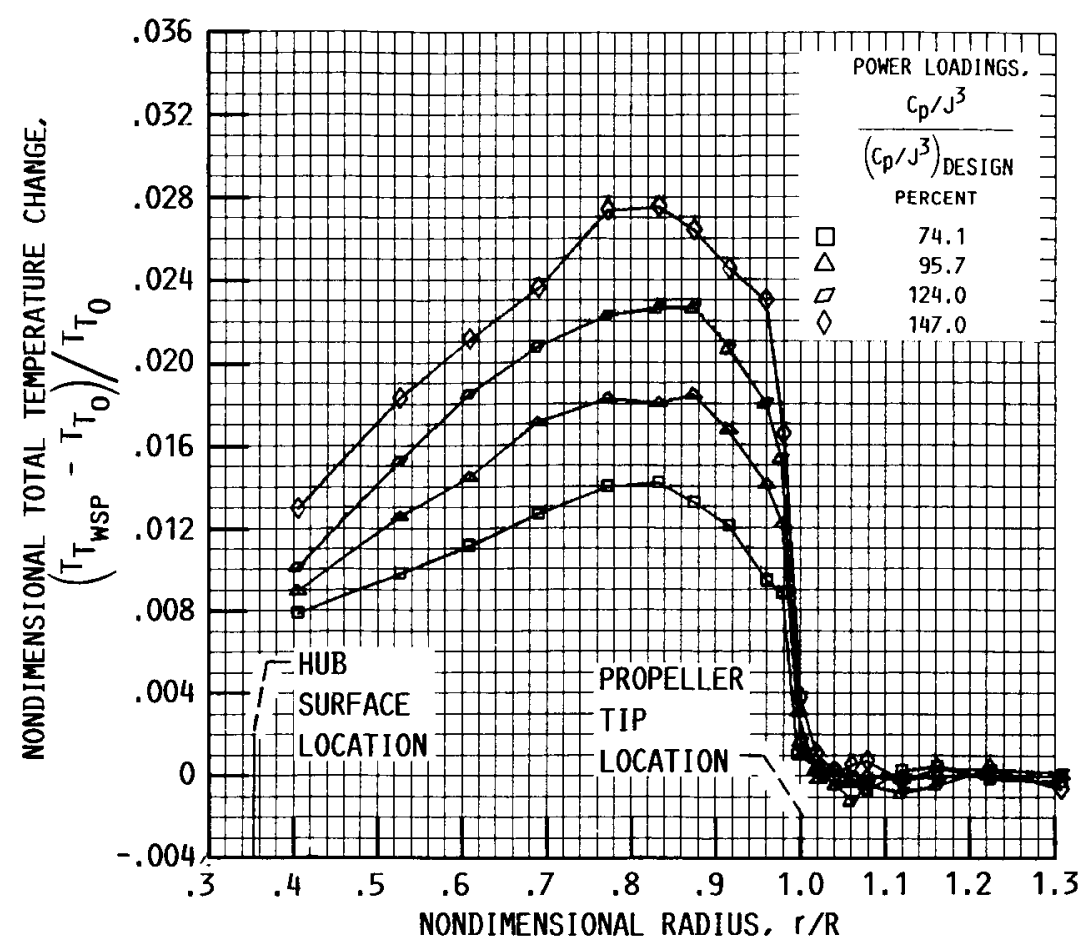

FIGURE 31. - COMPARISON OF NONDIMENSIONAL TOTAL TEMPERATURE DISTRIBUTIONS AT DIFFERENT POWER LOADINGS. $M=0.80, \beta_{0.75 R}-60.2^{0}$.

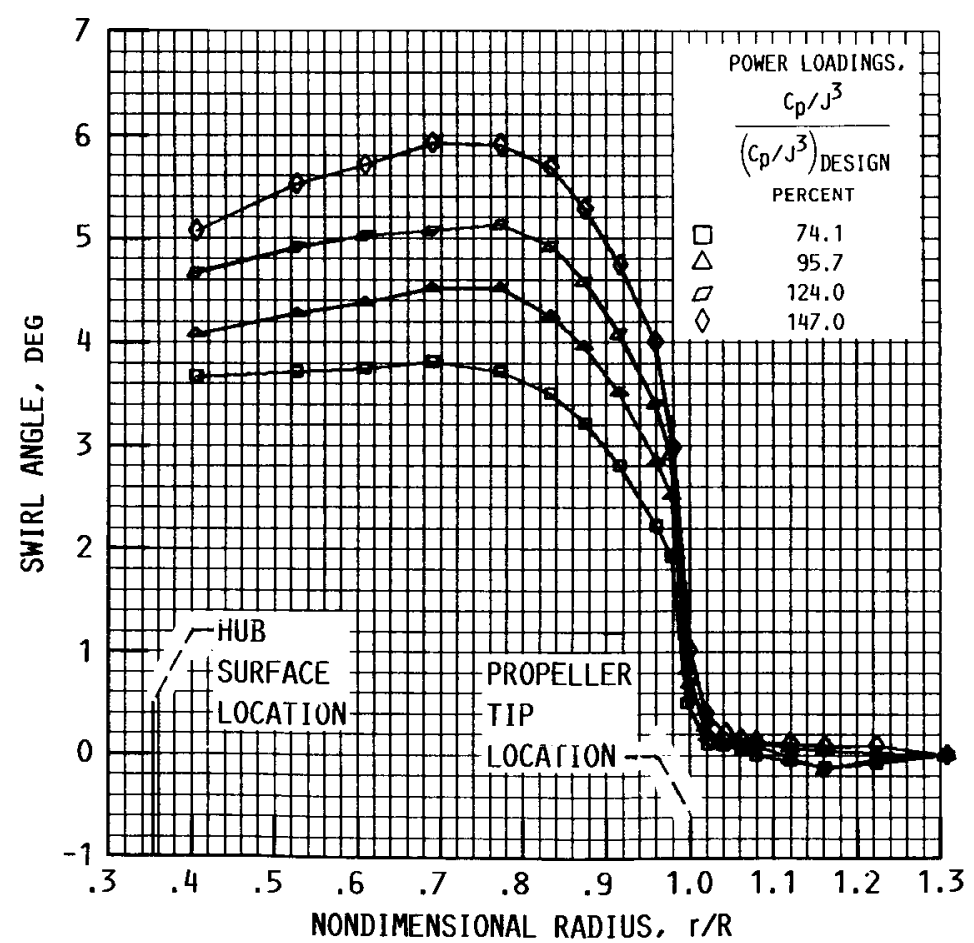

FIGURE 32. - COMPARISON OF RADIAL DISTRIBUTIONS OF SWIRL ANGLE AT DIFFERENT POWER LOADINGS. $M=0.80, \beta_{0.75 R}=60.2^{0}$. 


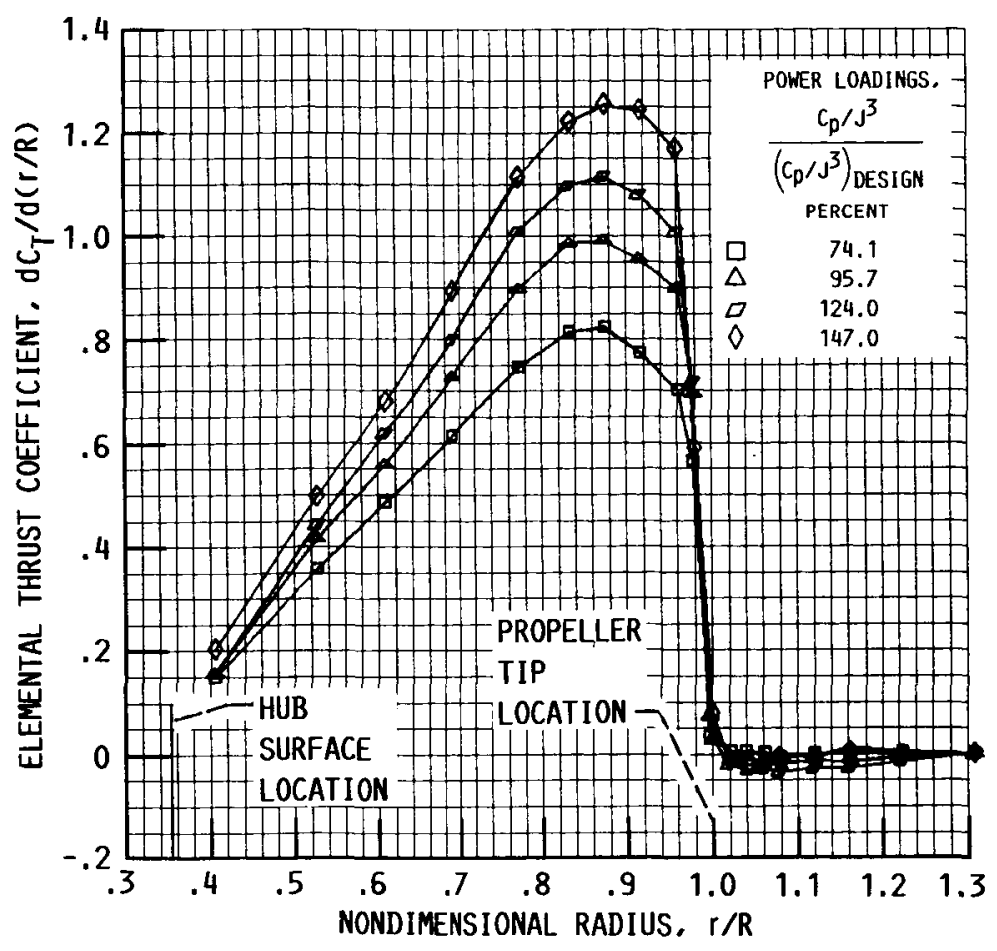

FIGURE 33. - COMPARISON OF ELEMENTAL THRUST COEFFICIENT DISTRIBUTIONS AT DIFFERENT POWER LOADINGS. $M=0.80, \beta_{0.75 R}=60.2^{\circ}$.

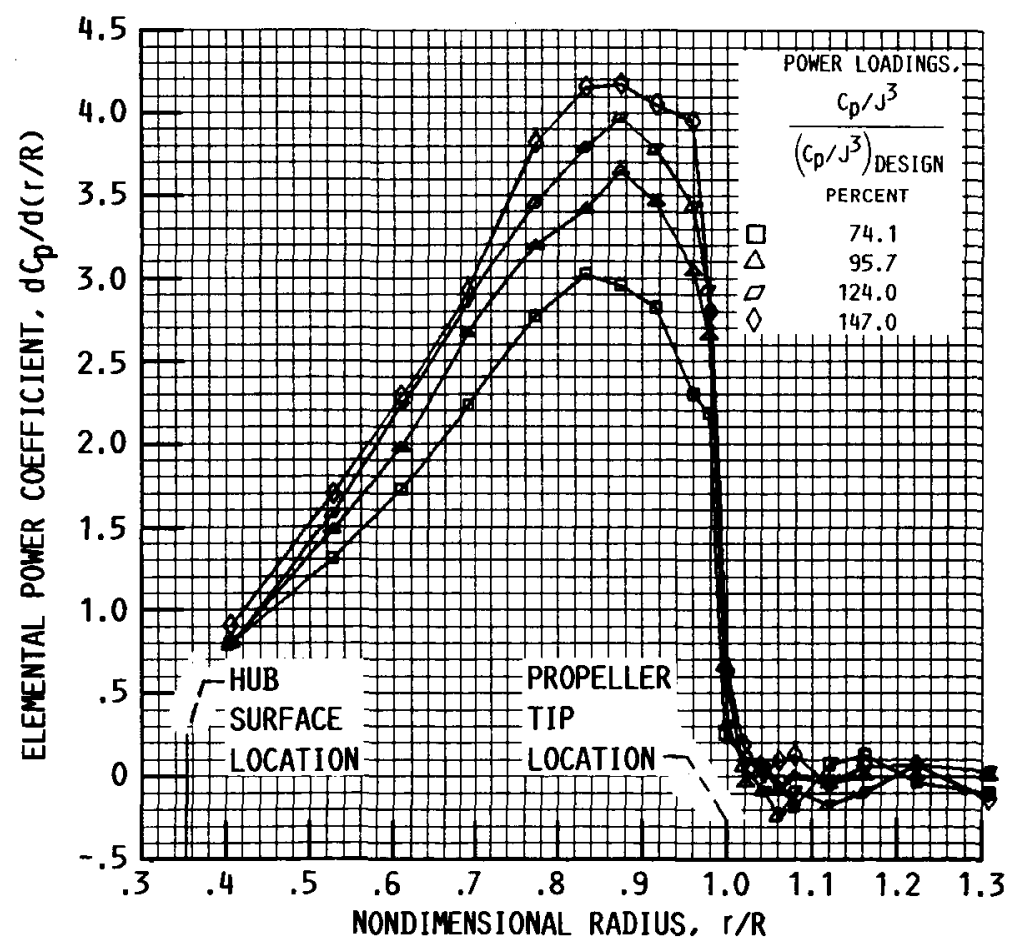

FIGURE 34. - COMPARISON OF ELEMENTAL POWER COEFFICIENT DISTRIBUTIONS AT DIFFERENT POWER LOADINGS. $M=0.80$, $\beta_{0.75 R}=60.2^{\circ}$. 


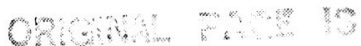

OF POOR QUAEIY

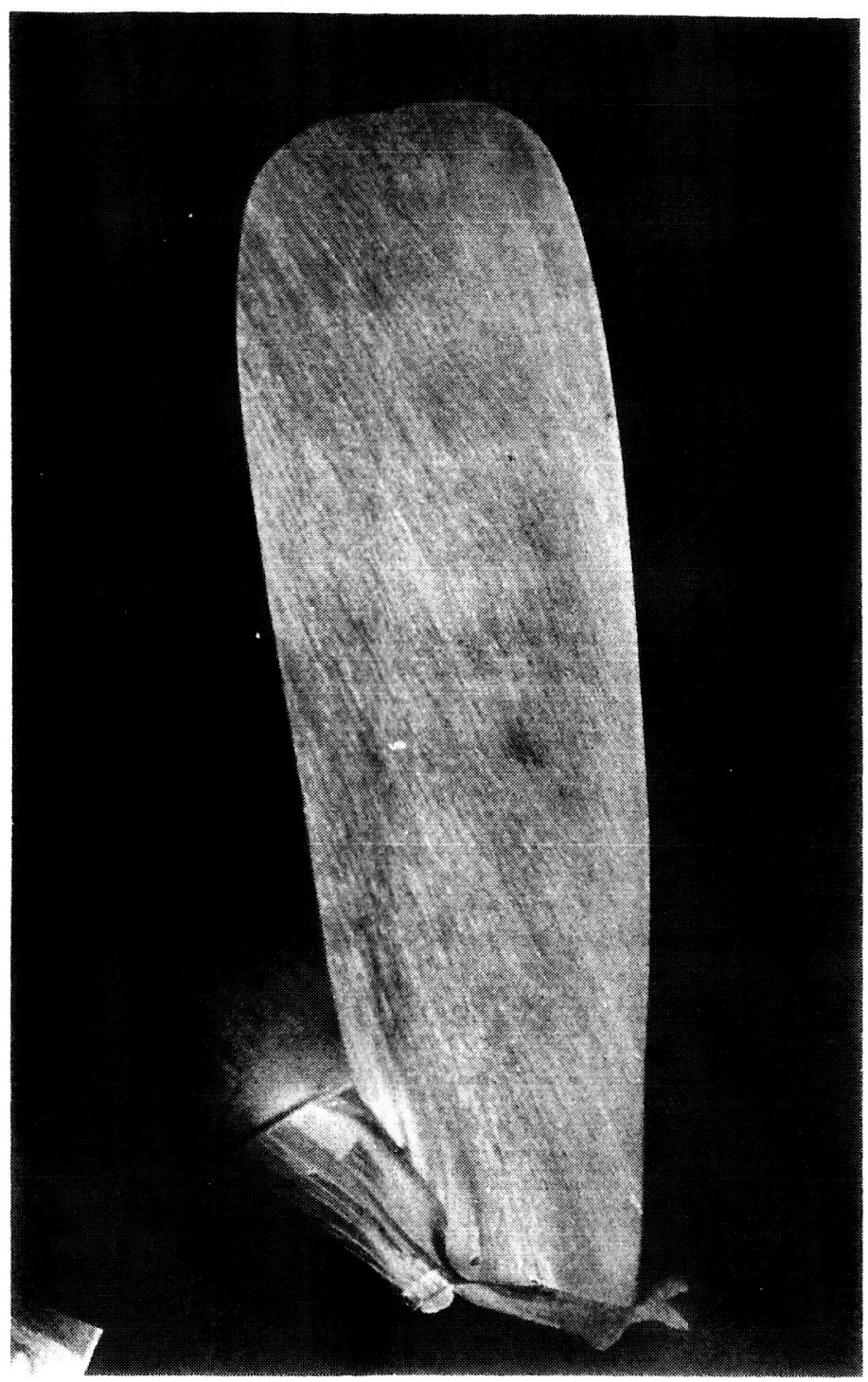

FIGURE 35. - FLUORESCENT OIL FLOW PATTERN ON THE STRAIGHT-BLADED SR-2 PROP-FAN SUCTION SIDE SHOWING NO LEADING EDGE VORTEX AT MACH 0.60 HIGH POWER CONDITIONS. $\left(J=3.01, C_{p}=1.59\right.$. $\beta_{0.75 R}=59.3^{\circ}$.) 


\section{QRIGINAL PAGE IS
OF POOR QUALITY}

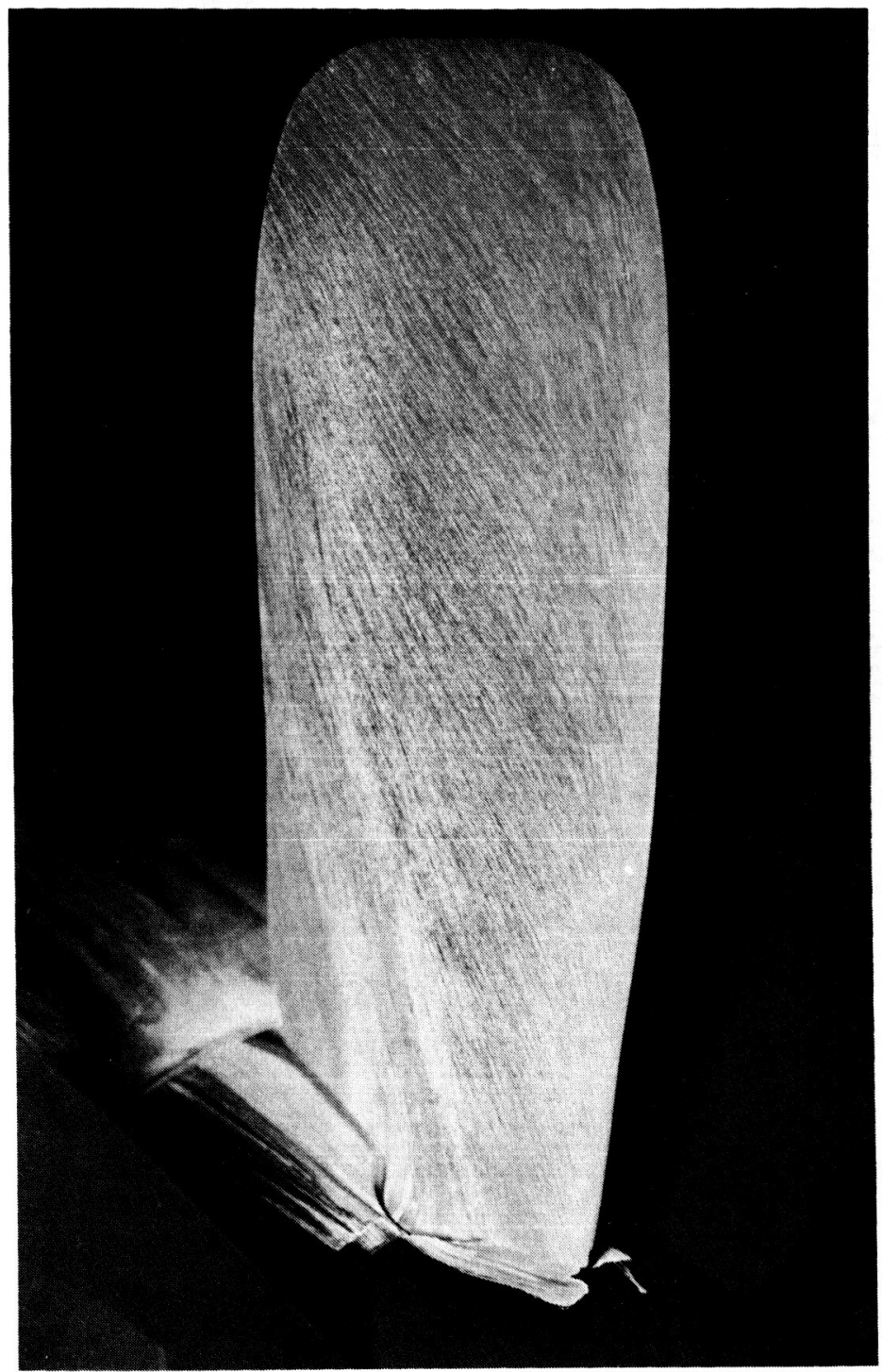

FIGURE 36. - FLUORESCENT OIL FLOW PATTERN ON THE STRAIGHT-BLADED SR-2 PROP-FAN SUCTION SIDE SHOWING NO LEADING EDGE VORTEX AT MACH 0.80 NEAR 100\% DESIGN POWER CONDITIONS. $(\mathrm{J}=3.03$. $C_{p}=1.69, \beta_{0.75 R}=59.3^{\circ}$. ) 


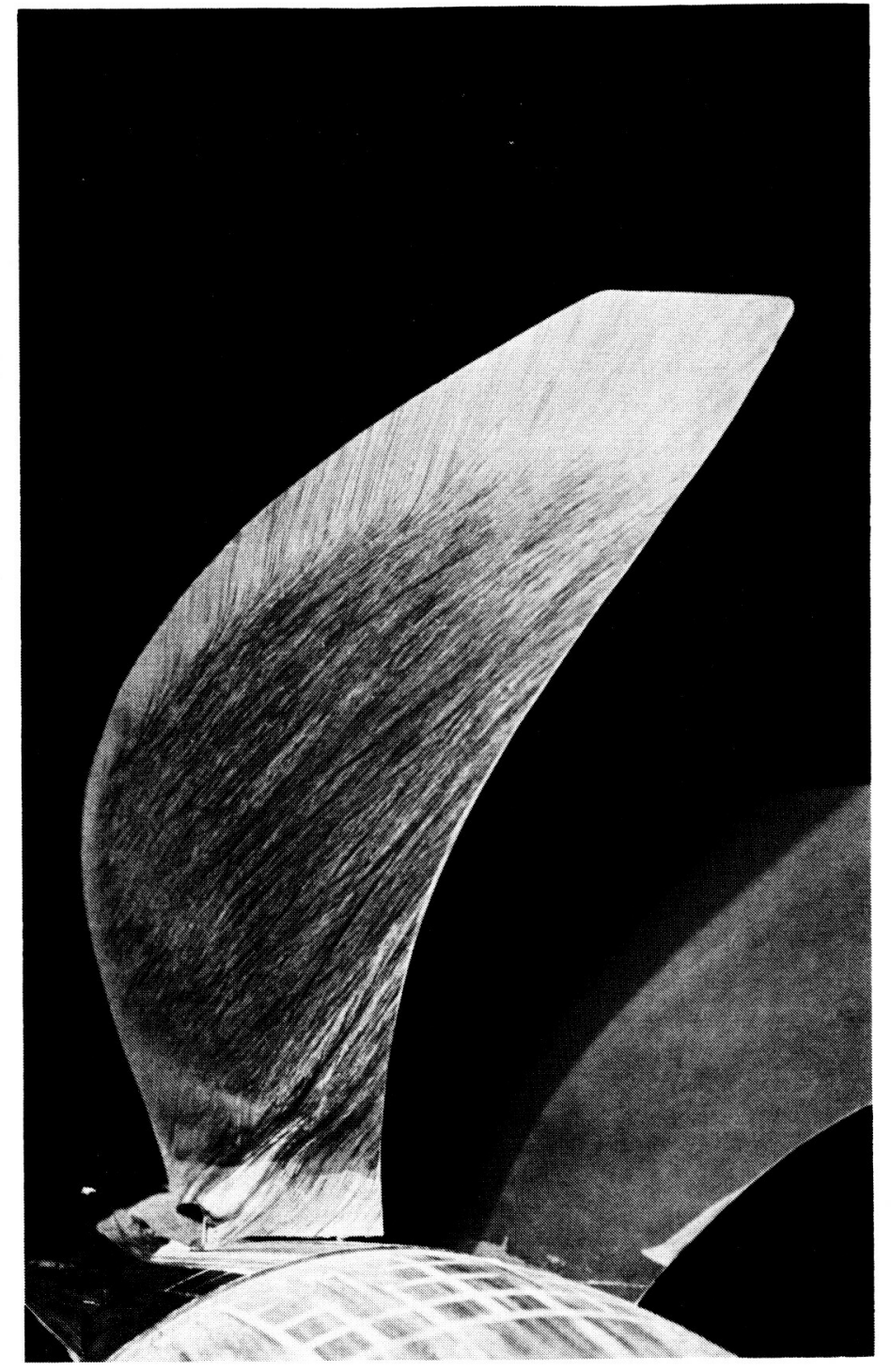

FIGURE 37. - FLUORESCENT OIL FLOW PATTERN ON THE $45^{\circ}$ SWEPT SR-3 PROP-FAN PRESSURE SIDE ILLUSTRATING THE LEADING EDGE VORTEX PATTERN AT MACH 0.80 WINDMILL CONDITIONS. $\left(J=4.52 . C_{p}=0 . \beta_{0.75 R}=62.0^{0}.\right)$ 


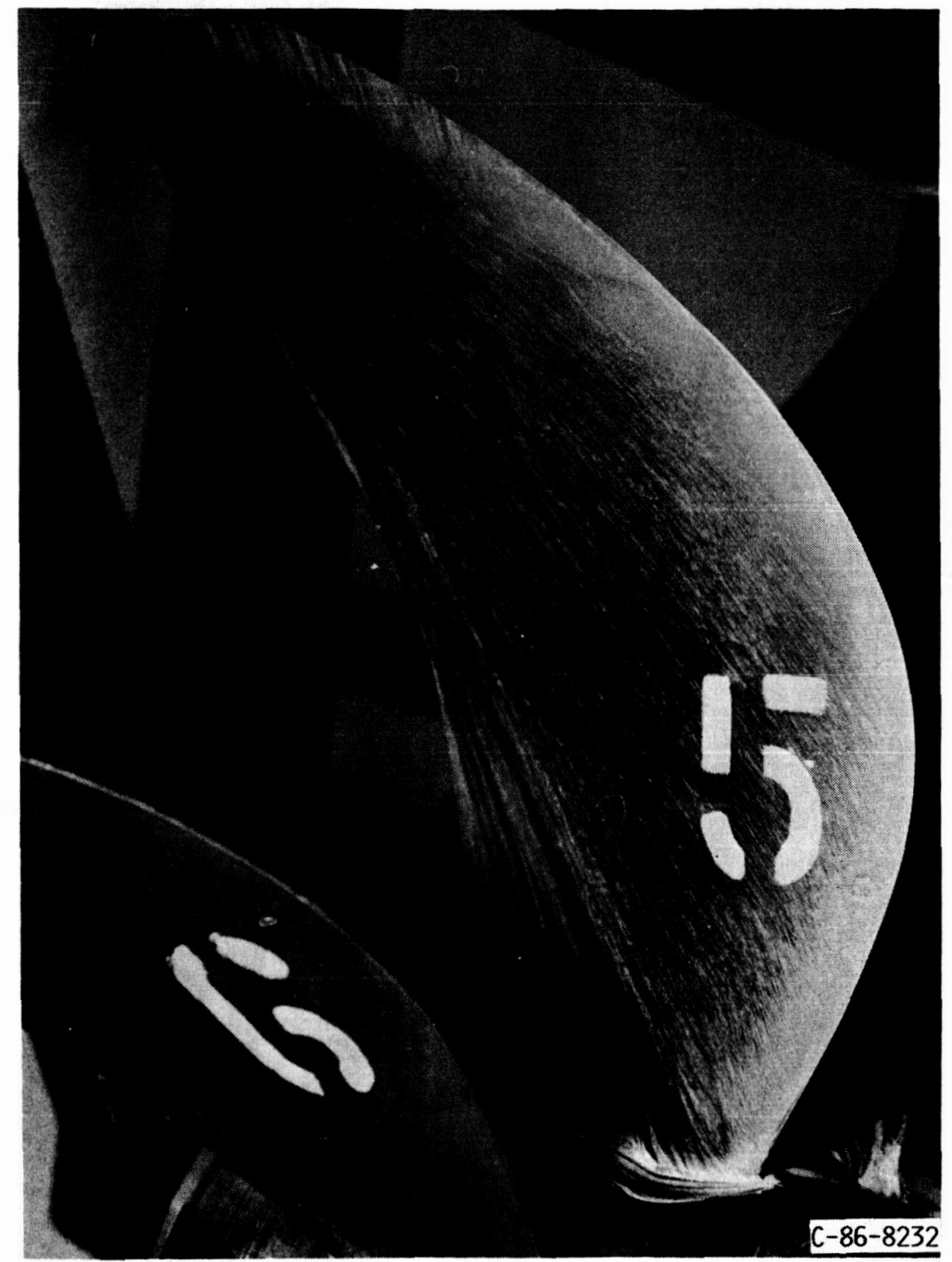

FIGURE 38. - FLUORESCENT OIL FLOW PATTERN ON THE $45^{\circ}$ SWEPT SR-3 PROP-FAN SUCTION SIDE SHOWING A SMALL LEADING EDGE VORTEX PATTERN AT MACH $0.60 \mathrm{HIGH}$ POWER CONDITIONS. $\left(\mathrm{J}=3.17, \mathrm{C}_{\mathrm{p}}=\right.$ 2.14. $B_{0.75 R}=62.0^{\circ}$.) 


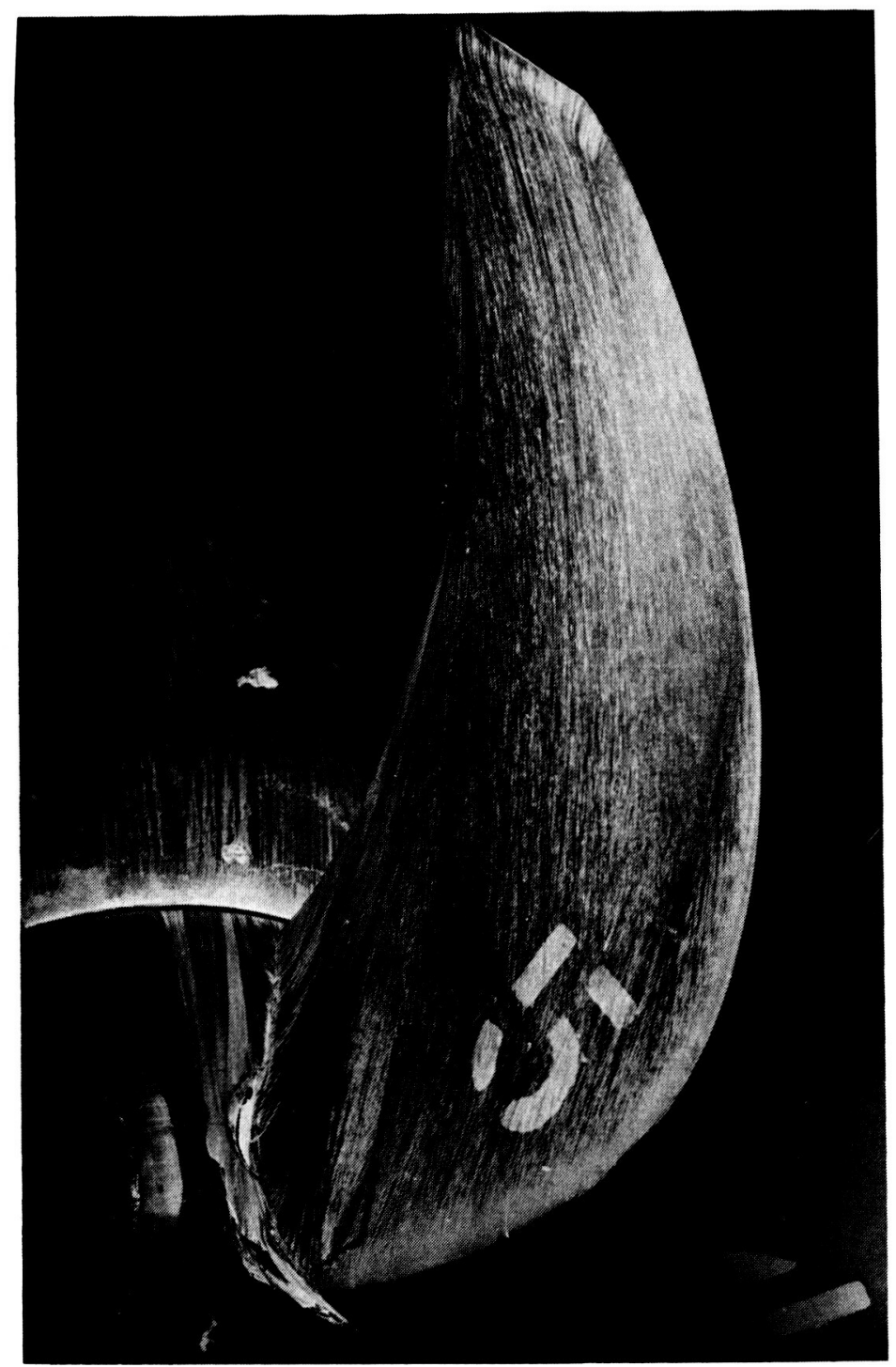

FIGURE 39. - FLUORESCENT OIL FLOW PATTERN ON THE $45^{\circ}$ SWEPT SR-3 PROP-FAN SUCTION SIDE SHOWING A SMALL LEADING EDGE VORTEX PATTERN AT MACH 0.80 NEAR 100\% DESIGN POWER CONDITIONS. $\left(J=3.21, C_{p}=1.99, \beta_{0.75 R}=62.0^{\circ}.\right)$ 
Ontenn:

of poon gintin

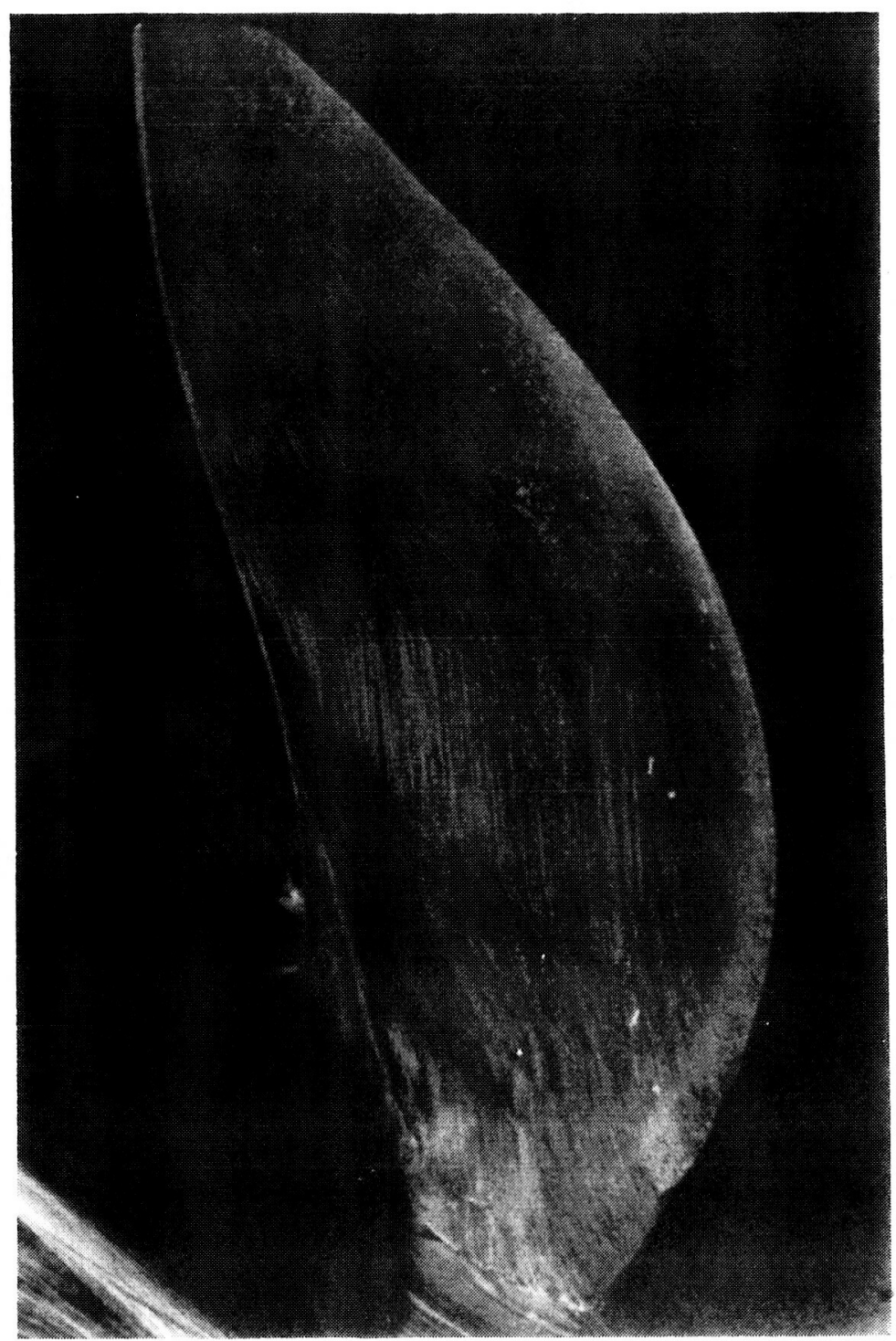

FIGURE 40. - FLUORESCENT OIL FLOW PATTERN ON THE $41^{\mathrm{U}}$ SWEPT SR-7A PROP-FAN SUCTION SIDE SHOWING A SMALL LEADING EDGE VORTEX PATTERN AT MACH $0.60 \mathrm{HIGH}$ POWER CONDITIONS. $\left(J=3.18, C_{p}=1.65, \beta_{0.75 R}=60.2^{0}.\right)$ 


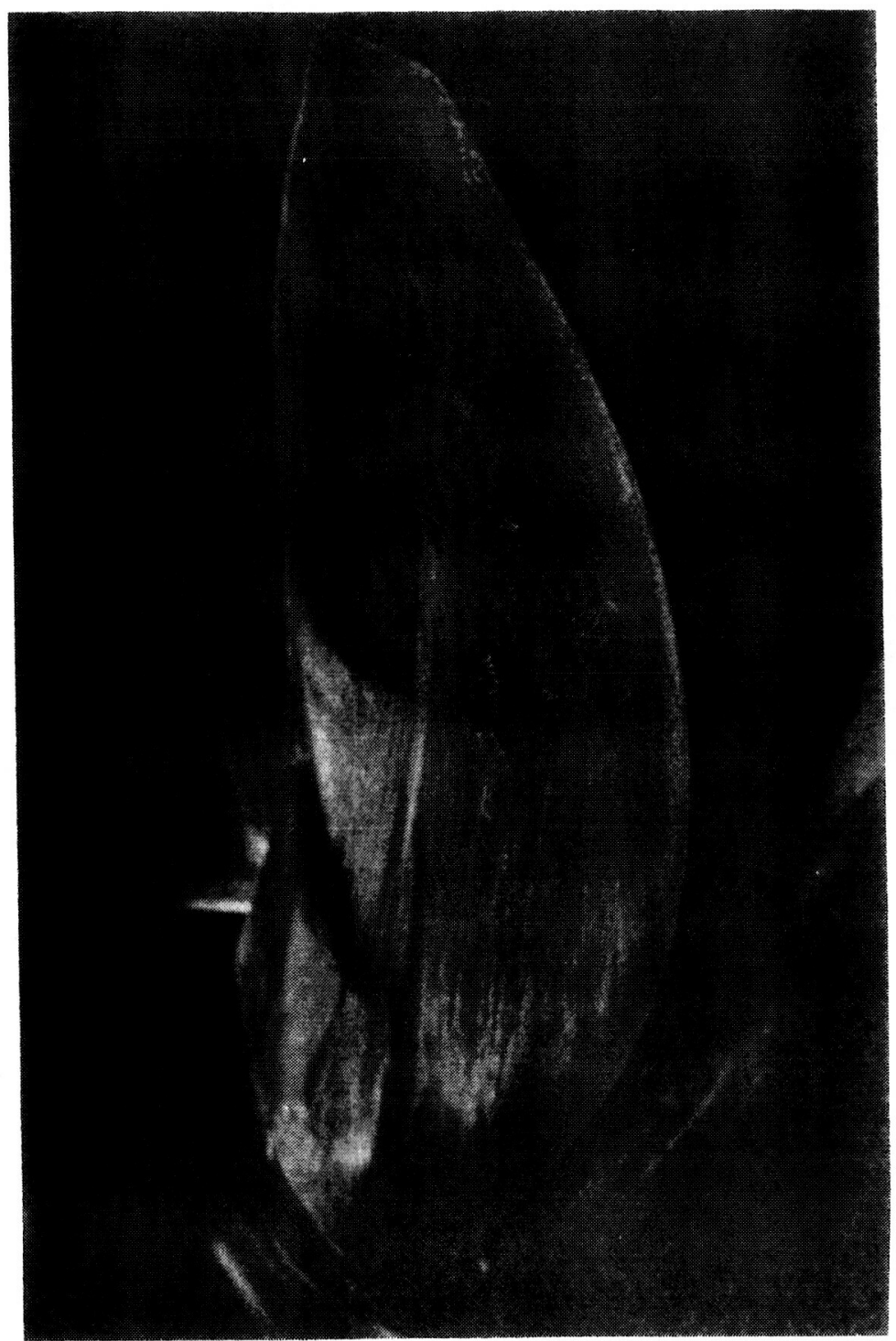

FIGURE 41. - FLUORESCENT OIL. FLOW PATTERN ON THE $41^{\circ}$ SWEPT SR-7A PROP-FAN SUCTION SIDE SHOWING A SLIGHT LEADING EDGE VORTEX PATTERN AT MACH 0.80 NEAR 100\% DESIGN POWER CONDITIONS. $\left(J=3.11, c_{p}=1.51\right.$. $\beta_{0.75 R}=60.2^{0}$.) 


\begin{tabular}{|c|c|c|}
\hline $\begin{array}{l}\text { 1. Report No. NASA TM-89917 } \\
\text { AIAA-87-1893 }\end{array}$ & n No. & 3. Recipient's Cataloo No. \\
\hline \multirow{2}{*}{\multicolumn{2}{|c|}{$\begin{array}{l}\text { 4. Title and Subtitle } \\
\text { Wind Tunne } 1 \text { Performance Results of an Aeroelastically } \\
\text { Scaled } 2 / 9 \text { Mode } 1 \text { of the PTA Flight Test Prop-Fan }\end{array}$}} & 5. Report Date \\
\hline & & $\begin{array}{l}\text { 6. Performing Organization Code } \\
545-03-01\end{array}$ \\
\hline \multicolumn{2}{|c|}{$\begin{array}{l}\text { 7. Author(s) } \\
\text { George L. Stefko, Gayle E. Rose, and Gary G. Podboy }\end{array}$} & $\begin{array}{l}\text { 8. Performing Organization Report No. } \\
\frac{\text { E-3610 }}{\text { 10. Work Unit No. }}\end{array}$ \\
\hline \multicolumn{3}{|l|}{ 9. Performing Organization Name and Address } \\
\hline \multirow{2}{*}{\multicolumn{2}{|c|}{$\begin{array}{l}\text { National Aeronautics and Space Administration } \\
\text { Lewis Research Center } \\
\text { Cleveland, Ohio } 44135\end{array}$}} & 11. Contract or Grant No. \\
\hline & & \multirow{2}{*}{$\begin{array}{l}\text { 13. Type of Report and Period Covered } \\
\text { Technical Memorand um }\end{array}$} \\
\hline \multicolumn{2}{|l|}{ 12. Sponsoring Agency Name and Address } & \\
\hline \multicolumn{2}{|l|}{$\begin{array}{l}\text { National Aeronautics and Space Administration } \\
\text { Washington, D.C. } 20546\end{array}$} & 14. Sponsoring Agency Code \\
\hline \multirow{2}{*}{\multicolumn{3}{|c|}{$\begin{array}{l}\text { 15. Supplementary Notes } \\
\text { Prepared for the 23rd Joint Propulsion Conference, cosponsored by the AIAA, SAE, ASHE, and ASEE, } \\
\text { San Diego, Cal ifornia, June } 29-\text { July } 2,1987 \text {. Ceorge L. Stefko and Gary G. Podboy, both of MASA } \\
\text { Lewis Research Center; Gayle E. Rose, Sverdrup Technology, Inc., Lewis Research Center, Cleveland, } \\
\text { Ohio } 44135 \text {. }\end{array}$}} \\
\hline & & \\
\hline \multicolumn{3}{|l|}{ 16. Abstract } \\
\hline \multicolumn{3}{|c|}{ 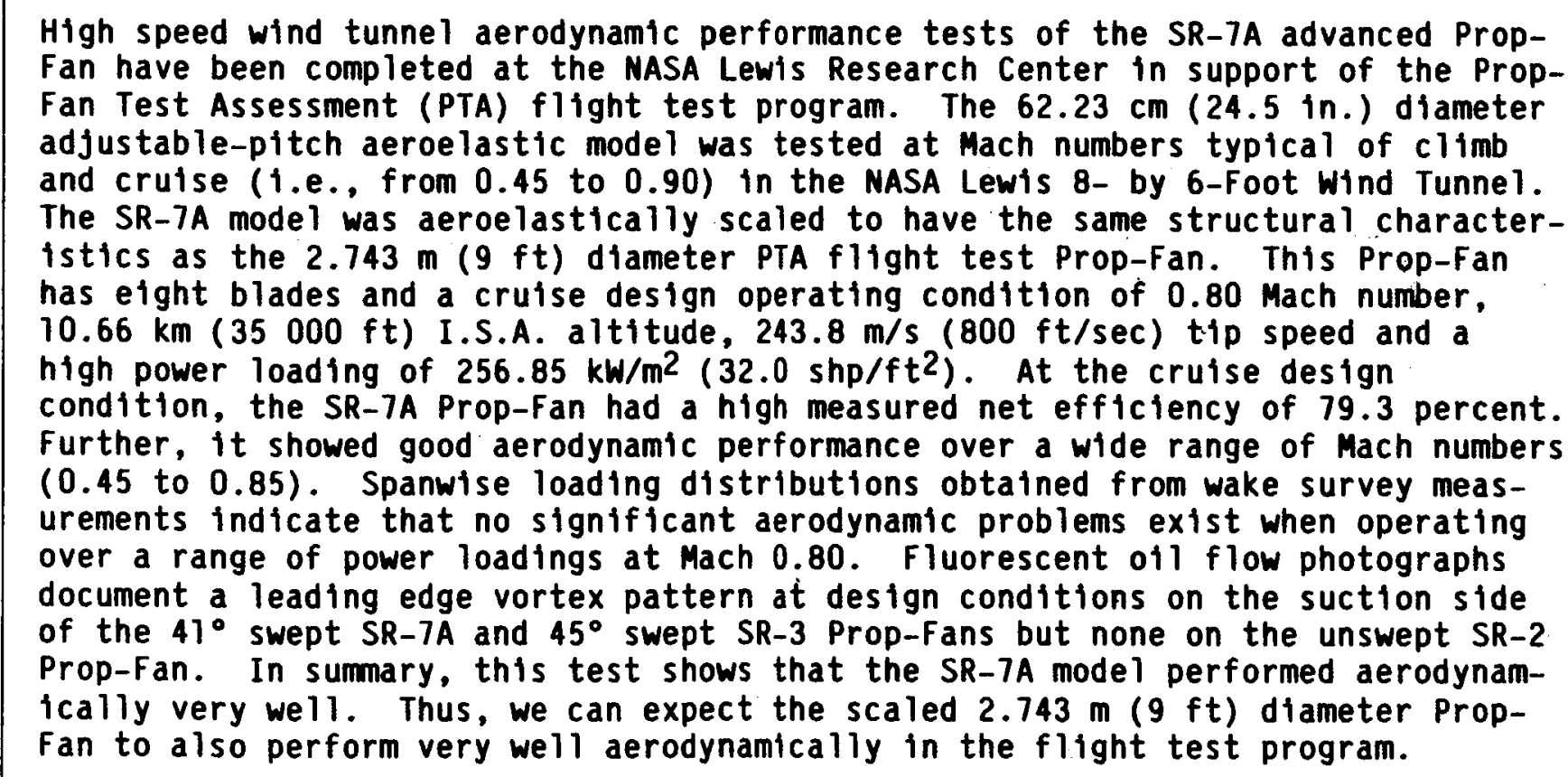 } \\
\hline 17. Key Words (Suggested by Author(s)) & \multirow{2}{*}{\multicolumn{2}{|c|}{$\begin{array}{l}\text { 18. Distribution Statement } \\
\text { Unc lass Ified - un } 1 \text { imited } \\
\text { STAR Category } 02\end{array}$}} \\
\hline $\begin{array}{l}\text { Prop-fan; Propellers; Advanced turboprop; } \\
\text { Energy efficient and supersonic tip speed }\end{array}$ & & \\
\hline $\begin{array}{r}\text { 20. Security Classiff. (of th } \\
\text { Unc las }\end{array}$ & & $\begin{array}{c}\text { 21. No. of pages } \\
49\end{array}$ \\
\hline
\end{tabular}

"For sale by the National Technical Information Service, Springfield, Virginia 22161 